\title{
Dry sliding wear behaviour of ultrasonically-processed AA6061/SiC nanocomposites
}

\author{
A. Prasad Reddy ${ }^{1}$, P. Vamsi Krishna ${ }^{2}$ and R. N. Rao ${ }^{3}$ \\ ${ }^{1}$ Mechanical Engineering Department, National Institute of Technology Warangal, \\ Telangana-506004, India \\ *Email: aprasadreddy43@gmail.com \\ Phone: +919704347052 \\ ${ }^{2,3}$ Mechanical Engineering Department, National Institute of Technology Warangal, \\ Telangana-506004, India
}

\begin{abstract}
The present study focused on the wear performance of AA6061/ SiCp (1, 1.5 and 2 wt. $\%$ ) of nanocomposites at dry sliding condition. The nanocomposite specimens were fabricated through ultrasonic assisted stir casting technique. The wear experiments were conducted under normal atmospheric conditions using a pin-on-disc apparatus. Three different applied normal loads on nanocomposite pin $(10 \mathrm{~N}, 15 \mathrm{~N}$, and $20 \mathrm{~N})$; at various sliding velocities of $(1 \mathrm{~m} / \mathrm{s}, 1.5 \mathrm{~m} / \mathrm{s}$, and $2 \mathrm{~m} / \mathrm{s})$; and at sliding distances of $(1000 \mathrm{~m}, 2000$ $\mathrm{m}$, and $3000 \mathrm{~m}$ ) were considered. The influences of applied normal load on nanocomposite pin, wt. \% of SiCp reinforcement particles, sliding velocity, and sliding distance on both friction coefficient and wear loss were studied. The changes of wear loss and friction coefficient with varying applied normal loads, sliding velocities, and sliding distances were plotted. It was observed that the wear loss increased linearly with increasing sliding distance and sliding velocity. This was due to the increase of oxidation layer on the pin surface. The average friction coefficient at sliding velocity $1 \mathrm{~m} / \mathrm{s}$ for 1 wt. \% of SiCp, 1.5 wt. \% of SiCp, and 2 wt. \% of SiCp reinforced nanocomposites at sliding distance $3000 \mathrm{~m}$, at $20 \mathrm{~N}$ normal loads was $0.29,0.43$, and 0.46 , respectively. The average friction coefficient at $2 \mathrm{~m} / \mathrm{s}$ sliding velocity for the same load and sliding distance was $0.26,0.27$, and 0.28 , respectively. The increase of $\mathrm{SiCp}$ reinforcement in the matrix increased the friction coefficient due to its cubic crystal structure. The increase of sliding velocity and sliding distances reduced the friction coefficient. The worn surfaces of the samples were examined using SEM and EDX analyses. SEM micrograph analysis of the wear surfaces of the nanocomposites exhibited the abrasion wear and oxidative wear with severe plastic deformation. The shallower scratches, circular grooves, and deeper grooves were identified at different conditions on the worn surfaces.
\end{abstract}

Keywords: AA6061; dry sliding; sliding velocity; wear loss; coefficient of friction; worn surface examination.

\section{INTRODUCTION}

Metal matrix composites (MMCs) play a significant role in wear, structural, electrical, and thermal applications of the present industry because of their superior properties (high specific strength to weight ratio and low cost) compared to base alloys. The properties of the MMC depends on the type of matrix material, type of reinforcement, reinforcement 
particle size and fabrication process [1-3]. The micron size reinforced metal matrix composites can achieve good strength; however, the ductility of the material reduces. The micron size particles have less surface area to volume ratio and act as micro-crack initiators in the matrix, which leads to a remarkable decrement in the ductility of the composites [3-6]. Many researchers proved that the ceramic nano-sized particle reinforced metal matrix composites attained good strength with similar ductility of the metal matrix [6-8]. Ceramic particles' influence on the ductility is less because of their large surface area to volume ratio, which leads to less crack initiation compared to micron-sized reinforced composites. However, the strength of the composites is influenced by uniform dispersion of reinforcements in the matrix. The homogeneous dispersion of nano ceramic reinforcements in the matrix is important because it provides an excellent balance between ceramic particles and inter-particle distance, and which extends the yield strength exponentially with good creep resistance [9]. Researchers investigated various lightweight metal matrix composite materials; among them, aluminium based metal matrix composites (AMMCs) materials are efficient due to their good permissible properties for the various industrial and structural applications, particularly for cylinder liners [10]. The particle reinforced aluminium metal matrix composites are easy to fabricate and they are isotropic compared to the fibre or whisker reinforced aluminium composites.

The aluminium metal matrix composites are replacing the aluminium alloys to avoid disadvantages such as poor wear resistance, poor corrosion resistance and lower strengths at elevated and room temperatures [11]. In many applications, wear is the main problem which decreases the lifespan of the components. The ceramic nanoreinforcement particles have a special attention to their outstanding properties such as high strength per density, high melting point, better wear resistance and good corrosion resistance [12]. The properties of aluminium metal matrix composites improve by reinforcing ceramic particles such as $\mathrm{SiCp}$ [13], $\mathrm{Al}_{2} \mathrm{O}_{3}$ [14], $\mathrm{B}_{4} \mathrm{C}$ [15], $\mathrm{TiB}_{2}$ [16], AlN [17], and TiC [18]. Among all the ceramic reinforcements, the SiCp ceramic particles reinforced aluminium based composites attain good mechanical properties and wear resistance. Goudarzi et al. [19] revealed that the addition of SiCp nanoparticles improved the wear resistance compared to micron size SiCp reinforcements in the aluminium matrix because the crack initiators are fewer in the case of nanoparticle reinforced composites compared to micron size particle reinforced composites. Rao et al. [20] investigated wear behaviour of the aluminium alloy ( $\mathrm{Al}-\mathrm{Zn}-\mathrm{Mg}$ )/SiCp composites at dry condition and reported that the wear properties and strength are better than that of base alloy. Similar studies in dry sliding condition on AA7010/SiCp, AA7009/SiCp, AA2024/SiCp and (Al$\mathrm{Cu}-\mathrm{Mg}$ )/SiCp composites exhibited that the wear resistance was significantly higher than that of the base material [21, 22]. Hassan et al. [23] examined the wear behaviour of aluminium alloy ( $\mathrm{Al}-\mathrm{Mg}-\mathrm{Cu}) / \mathrm{SiCp}$ composites at dry condition and reported that silicon carbide particles shared the main role in improving the wear resistance of the base alloy. Suresha et al. [24] reported that the $\mathrm{Al} / \mathrm{SiCp}$ reinforced composites have higher strength and wear resistance than pure aluminium. Mazahery et al. [25] found that the wear behaviour of AA6061 alloy at dry condition by reinforcing various sizes of SiCp micronsized particles in the matrix resulted in better wear resistance compared to the base material and better wear resistance is achieved with lower reinforcement particle size. Sivaiah et al. [26] studied the wear behaviour of the AA5083/SiCp nanocomposites at dry condition and they revealed a significant improvement in specific wear rate compared to the base material. Darmiani et al. [27] studied the wear behaviour of AA1050/SiCp nanocomposites in dry sliding condition and found that the wear resistance improved by 
increasing the number of roll bonding cycles. Many investigators observed that the wear resistance of the composites increased with increasing the weight percentage of reinforcements in matrix material [28]. However, the hardness of the composites increased with increase in the weight percentage of the ceramic reinforcements in the matrix material. The wear resistance increased by increasing the hardness of the composites. The literature supports and confirms that the wear properties of nanoparticles reinforced aluminium metal matrix composites are better than matrix alloy.

The objective of the present research work is to fabricate AA6061/ SiCp (1, 1.5, and 2 wt. \%) of metal matrix nanocomposites by ultrasonic assisted stir casting technique and to evaluate the wear properties. In this study, the effects of SiCp reinforcement quantity in the matrix, sliding velocity, applied normal loads on pin and sliding distance on the friction coefficient and wear properties of the nanocomposites were studied. The Scanning Electron Microscope (SEM) images and Energy Dispersive X-Ray (EDX) spectrum of the wear surfaces of the nanocomposites were analysed to understand the type wear mechanism.

\section{METHODS AND MATERIALS}

\section{Experimental Details \\ Materials}

A commercial ingot of an AA6061 alloy at T6 condition with a formal composition of Al-0.95 Mg-0.54Si-0.22Fe-0.13Mn-0.17Cu-0.09Cr-0.08Zn-0.02Ni-0.01Ti was used as the matrix material and nano silicon carbide was chosen as reinforcement. The AA6061 alloy was supplied by Bharat Aerospace Metals, India. The beta phase silicon carbide (SiCp) nano-reinforcements with an average particle size in between 45-65 nm of purity 99\% were supplied by US Research Nanomaterials, Inc, USA. The crystal structure of silicon carbide is cubic. The details of the AA6061 alloy and SiCp nanoparticles are provided in Table 1. The as-received SiCp nanoparticles and AA6061alloy were observed for their size and purity by using SEM (Figure 1) and XRD (Figure 2). The peaks of Al

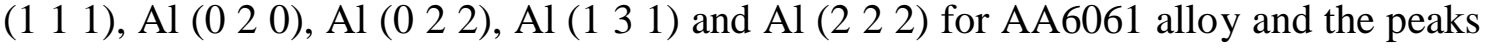
of SiCp (1 1 1), SiCp (2 0 0), SiCp (2 20 ), SiCp (2 20 ) and SiCp (3 11 1) for $\beta$-SiCp nanoparticles were recognised through Joint Committee on Powder Diffraction Standards (JCPDS) software analysis.

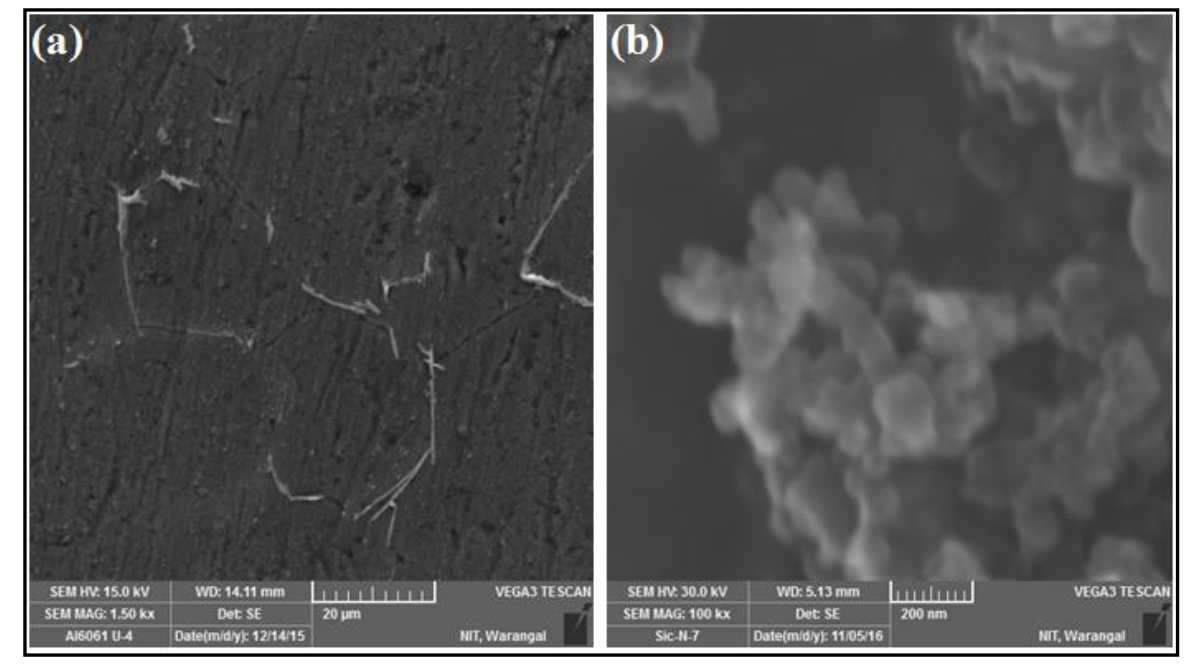

Figure 1. As-received material SEM image of (a) AA6061 alloy; (b) SiCp nanoparticles. 
Table 1. Properties of raw materials [29].

\begin{tabular}{cccc}
\hline Material & Density $\left(\mathrm{g} / \mathrm{cm}^{3}\right)$ & Melting Point $\left({ }^{\circ} \mathrm{C}\right)$ & $\begin{array}{c}\text { Coefficient of thermal expansion } \\
\left(\mathrm{m} / \mathrm{m} .{ }^{\circ} \mathrm{C}\right)\end{array}$ \\
\hline AA6061 & 2.7 & 620 & $23 \times 10^{-6}$ \\
SiCp & 3.216 & 2730 & $5.12 \times 10^{-6}$ \\
\hline
\end{tabular}

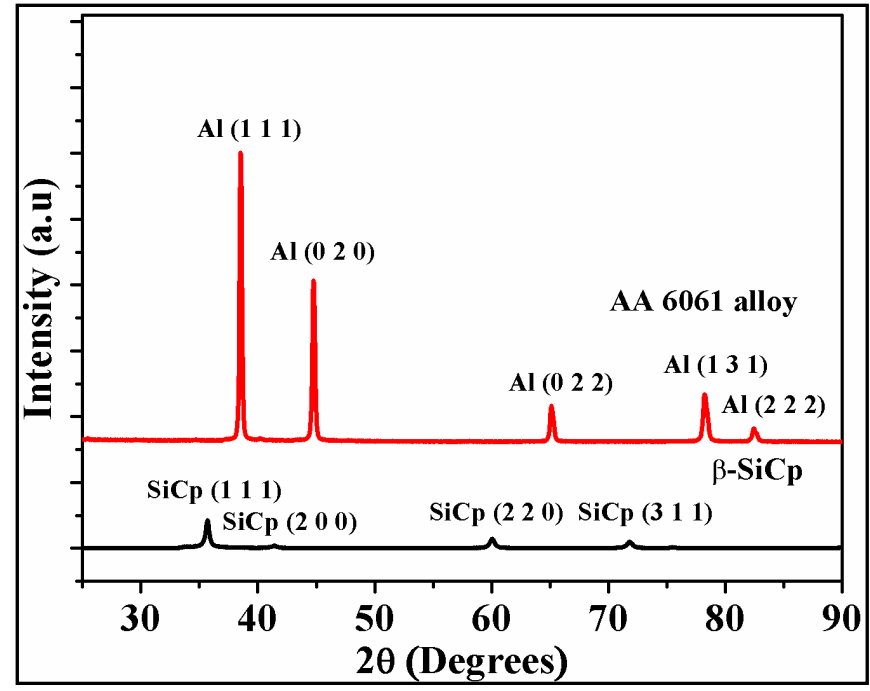

Figure 2. As-received AA6061 alloy and SiCp XRD patterns.

\section{Fabrication of Nanocomposites}

The nanocomposites were synthesised through the Ultrasonic assisted casting technique with the combination of AA6061 alloy and 1, 1.5, and 2 wt. \% of SiCp nanoreinforcements. The ultrasonic assisted casting setup used for synthesis of nanocomposites is shown in Figure 3. The ultrasonic assisted casting method is a liquid state process. In this technique, the ultrasonic energy produced the nonlinear effects into the molten metal such as cavitation and acoustic streaming. In the ultrasonic cavitation process, small-sized transient zones were created in the molten melt and subjected to high pressures and temperatures with high heating and cooling rates. During this process, shock force incorporated with local high temperatures and disintegrated the clusters, which cleaned the surface of the nano SiCp reinforcement particles. In this process, the dissolved gases can be removed, molten metal purified, grain size reduced, and the wettability in between the matrix and the reinforcement particles was improved. The reinforcement particles distribution in the metal matrix and grain refinement depended on the ultrasonic intensity. Wettability and interface bonding between nano-sized SiCp reinforcement and matrix material were good in the ultrasonic assisted casting method [30]. Ultrasonic apparatus was equipped with maximum output frequency of $20 \mathrm{kHz}$ and maximum power of $2.4 \mathrm{~kW}$. Initially, AA6061 alloy ingots of 500 grams were melted at $750^{\circ} \mathrm{C}$ temperature in a $150 \mathrm{~mm}$ height and $70 \mathrm{~mm}$ diameter graphite crucible by resistance heating furnace. The SiCp nano reinforcement particles were folded in aluminium foil and preheated to $550^{\circ} \mathrm{C}$ in a muffle furnace. The preheated wrapped aluminium foil was fed into the bottom of the graphite crucible with the help of a plunger. Then, the molten metal was mechanically stirred using a stirrer at $80 \mathrm{rpm}$. The constant rotational speed was maintained for $10 \mathrm{~min}$ to have a complete mixing. Later, the 
ultrasonic probe made of titanium alloy was dipped to a depth of $30 \mathrm{~mm}$ from the top surface of the molten slurry.

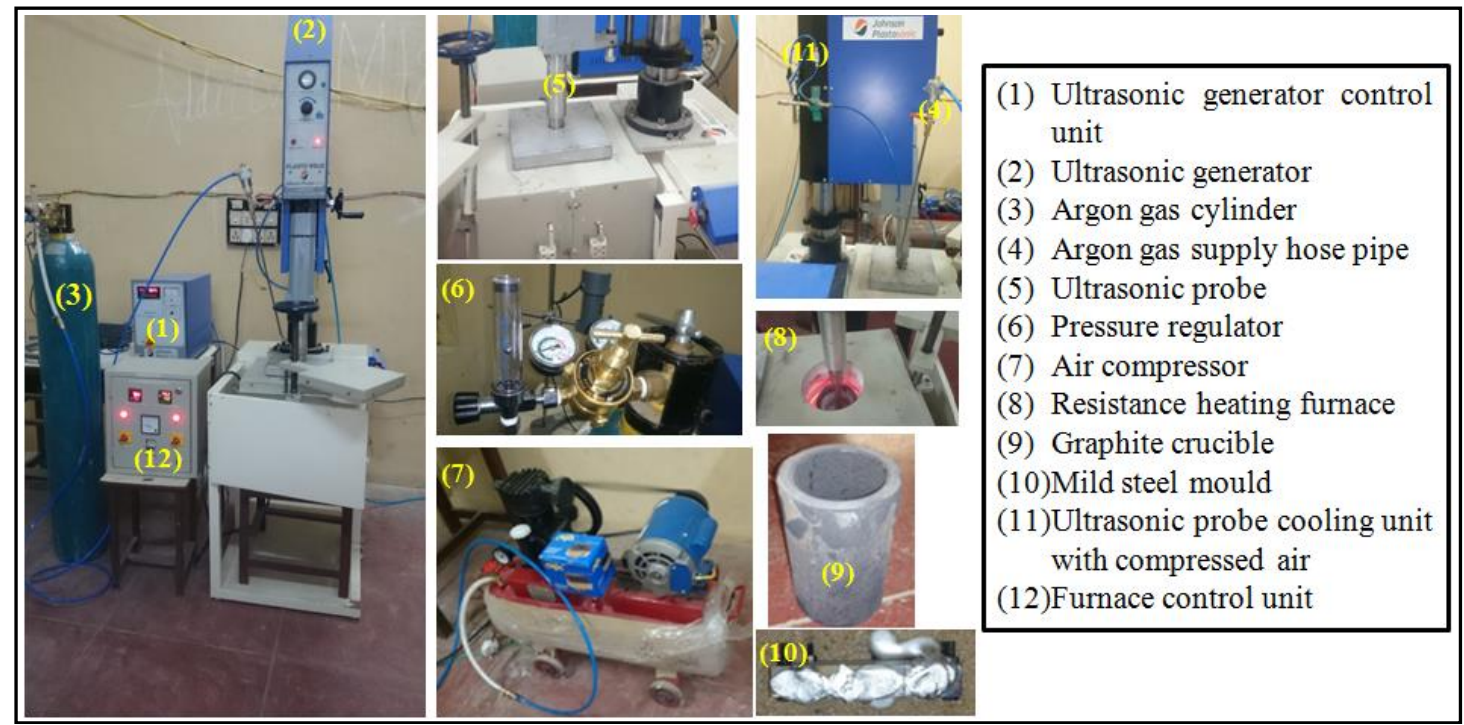

Figure 3. Ultrasonic assisted casting setup.

The ultrasonic processing frequency $20 \mathrm{kHz}$ was used for sonication. Subsequently, the mixture of molten slurry was processed with ultrasound energy wave for 25 min to break up the clustered nano reinforcement particles. Later, in the ultrasonic sonication, the graphite crucible was instantly removed from the resistance heating furnace, and a slurry of molten metal was poured into the mild steel mould. The mould was preheated to $550^{\circ} \mathrm{C}$ which was formerly filled with the slurry of molten aluminium. The samples were made for testing using wire cut Electrical Discharge Machining (EDM) as per the American Society for Testing and Materials (ASTM) standard dimensions. For microstructural examination, the samples were prepared by polishing the nanocomposites specimens with emery paper from 200 grit size to 1200 grit size and 1/0, 2/0, 3/0, and 4/0 grit size, subsequently followed by polishing with alumina suspension on the grinding machine using a velvet cloth. The polished nanocomposites surface was etched with Keller's reagent solution. The morphology of the nanocomposites was investigated using SEM.

The wear experiments were conducted at dry conditions as per G 99 ASTM standards (pin diameter $8 \mathrm{~mm}$, length $25 \mathrm{~mm}$ ) on AA6061/SiCp nanocomposites using the pin-on-disc setup of Magnum make, model-TE-165 (Figure 4). The material of the disc used in the tests was EN31 steel. Before performing the experiments, the nanocomposite pins and steel disc EN31 surface were cleaned with acetone. The experiment was conducted on the nanocomposites with applied normal loads of 10, 15, and $20 \mathrm{~N}$ on the pin at sliding velocities of $1,1.5$, and $2 \mathrm{~m} / \mathrm{s}$ and at sliding distance in steps of $250 \mathrm{~m}$ up to $3000 \mathrm{~m}$. After performing the wear experiments, the specimen surface and counter steel disc surface were cleaned with organic solvents to remove traces of composite. The weight of the samples was measured before and after the experiments to an accuracy of $0.1 \mathrm{mg}$ to get the amount of wear loss. Experiments were conducted in triplicate and the average values were taken for analysis. 


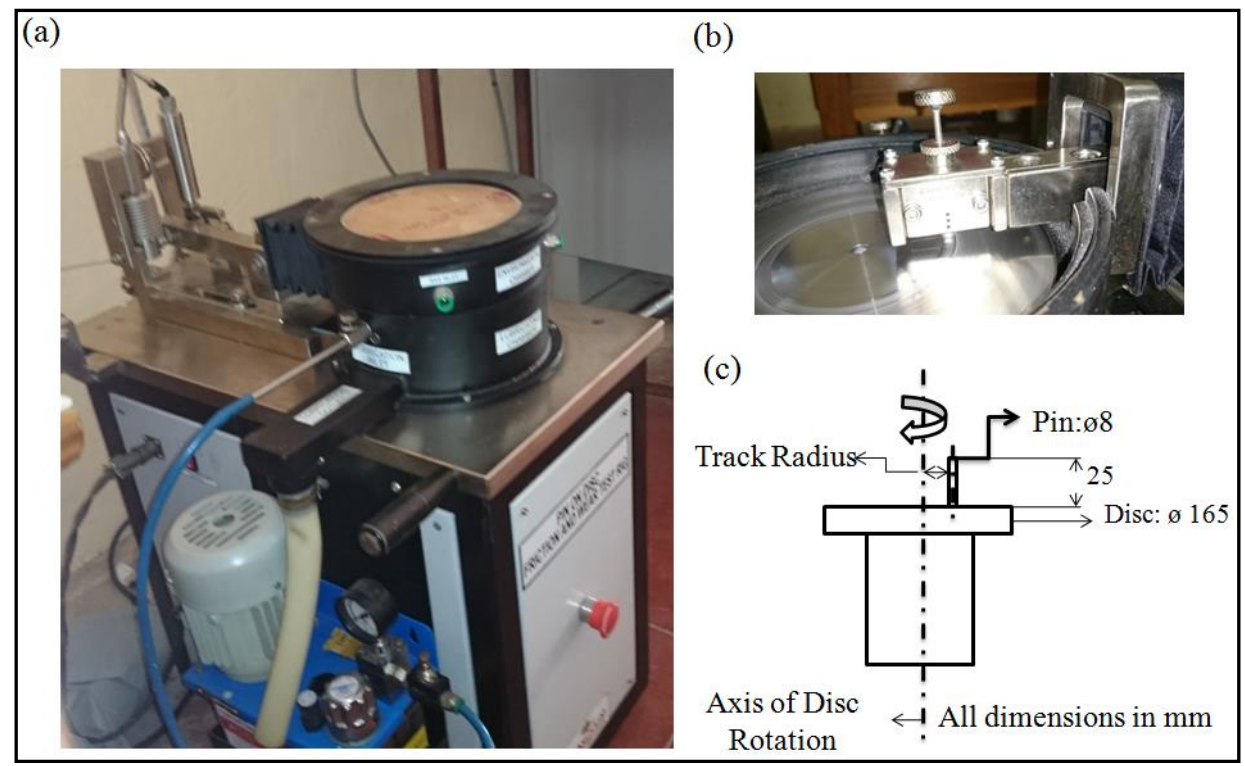

Figure 4. (a) Pin-on-disc apparatus; (b) pin holder setup; (c) dimensions of Pin-on-disc machine.

\section{Microstructure and X-ray Diffraction analysis}

The SEM micrographs of nanocomposites were verified for dispersion of $\mathrm{SiCp}$ reinforcement nanoparticles in the AA6061 alloy matrix. The SEM micrographs of AA6061/ (1, 1.5 and 2) wt. \% of SiCp nanocomposites are shown in Figure 5. In the SEM micrographs, ' $\mathrm{P}$ ' represents the SiCp nanoparticles and ' $\mathrm{C}$ ' denotes the cluster of SiCp nanoparticles. It was observed that the $\mathrm{SiCp}$ nano-reinforcements were dispersed uniformly in AA6061 alloy matrix material. However, small scale clusters of nano SiCp were observed in the microstructure on the grain boundaries and in the matrix. The peaks

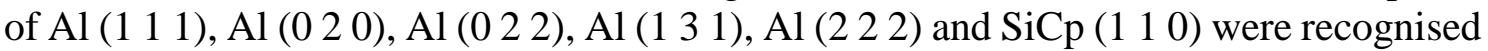
through JCPDS software in XRD analysis of the AA6061/SiCp nanocomposites (Figure 6). From XRD patterns, high-intensity peaks of aluminium and small intensity peaks of SiCp reinforcement nanoparticles were observed in the AA6061matrix.
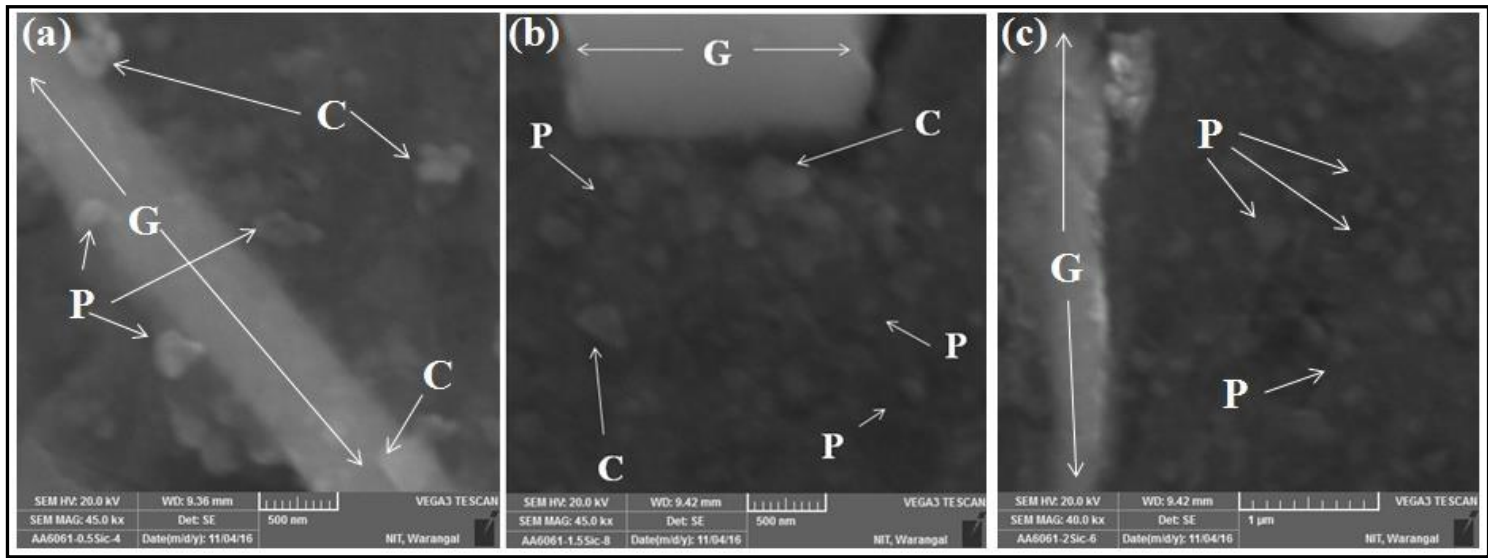

Figure 5. SEM micrographs of AA6061/SiCp reinforced nanocomposites (a) 1 wt. \%;

(b) 1.5 wt. $\%$; (c) 2 wt. \%. 


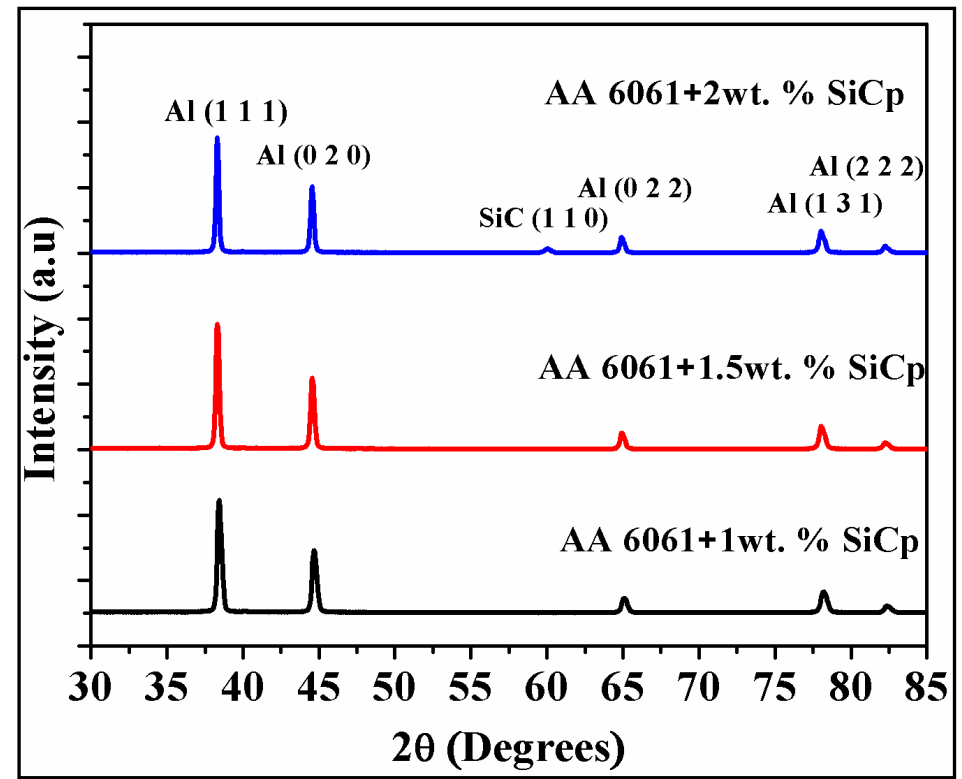

Figure 6. XRD pattern of AA6061/SiCp nanocomposites.

\section{RESULTS AND DISCUSSION}

The effects of various process parameters on wear loss and coefficient of friction of AA6061/SiCp nanocomposites were studied. The results obtained from the wear tests performed on nanocomposites with different applied normal loads, sliding velocities and sliding distance are discussed in the following sections.

\section{Effect of SiCp weight percentage on wear loss}

The wear loss of the nanocomposites with respect to the weight percentage of reinforcements is represented in Figure 7. The wear loss of the AA6061/SiCp nanocomposites decreased linearly with increasing the weight percentage of SiCp reinforcements in the matrix.

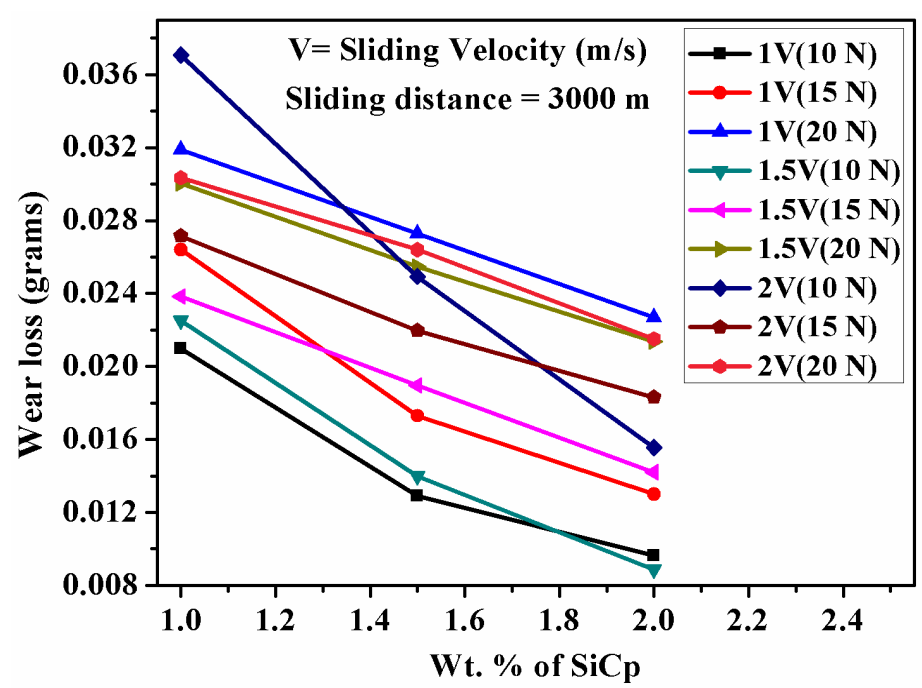

Figure 7. AA6061/SiCp nanocomposites with varying weight percentages of SiCp reinforcements. 
The lower wear loss was exhibited at $2 \mathrm{wt}$. \% of SiCp reinforced nanocomposites at $10 \mathrm{~N}$ normal loads and at a $1.5 \mathrm{~m} / \mathrm{s}$ sliding velocity. The higher wear loss resulted in 1 wt. \% of SiCp reinforced nanocomposites at $10 \mathrm{~N}$ normal loads and at a $2 \mathrm{~m} / \mathrm{s}$ sliding velocity. The wear loss was low with the increasing wt. \% of SiCp reinforcements in the matrix and rose with the increasing normal loads and decreased at higher sliding velocity. At higher sliding velocity, the frictional heat increased and softened the pin surface, which led to the formation of oxide thin film on the surface [31]. Then, it tends to disengage from the pin material on steel disc at higher sliding velocity.

\section{Effect of Normal Load on Wear Loss}

The wear loss of the nanocomposites with respect to normal loads at $3000 \mathrm{~m}$ sliding distance and at various sliding velocities is presented in Figure 8. The wear loss of the nanocomposites increased linearly with increasing normal loads and decreased as a function of increasing the weight percentage of reinforcements. The major portion of the applied load was carried by $\mathrm{SiCp}$ reinforcement particles. The role of the SiCp reinforcement particles was to support the contact stresses, preventing high plastic flows and abrasion between contact surfaces and hence reducing the amount of worn material. The SiCp reinforcements in the matrix facilitated the compaction of the oxide thin film in between the particles. However, if the load exceeded a critical value, the particles will be fractured and comminuted, losing their role as load supporters [23, 32]. Fragments of fractured $\mathrm{SiCp}$ reinforcement particles might also be mixed within the oxide layer, enhancing the hardness and wear resistance of the oxide thin film. These oxide thin films were more in the case of $\mathrm{SiCp}$ reinforced composites than the base alloy. The benefits of $\mathrm{SiCp}$ reinforcement were evident in lower wear loss of the nanocomposites when oxidation was present $[33,34]$. The change in wear loss was low, up to $15 \mathrm{~N}$ loads and it was high above $20 \mathrm{~N}$ normal loads on pin material.

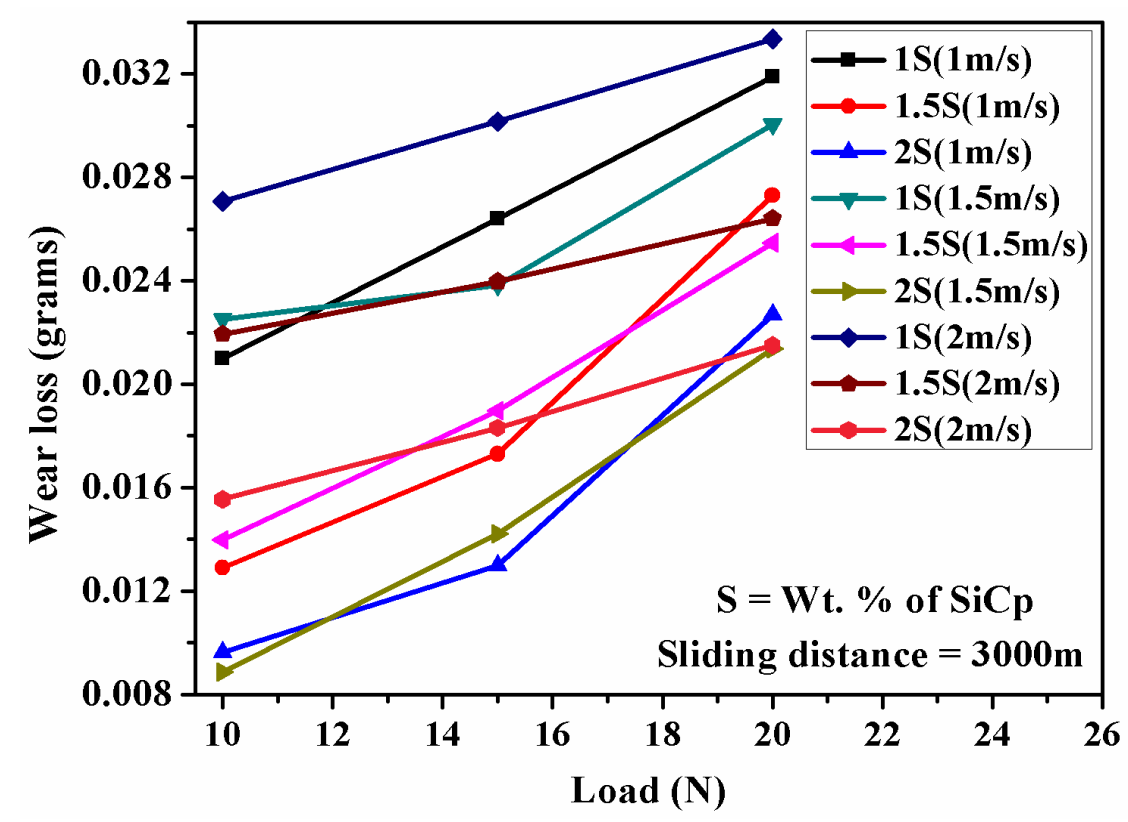

Figure 8. AA6061/SiCp nanocomposites wear loss at different conditions as a function of normal loads. 


\section{Effect of Sliding Distance on Wear Loss}

The AA6061/SiCp nanocomposites wear loss with varying sliding distances is shown in Figure 9. The results revealed that for all the given specimens, the wear loss linearly increased with the increasing sliding distance up to $3000 \mathrm{~m}$ in steps of $250 \mathrm{~m}$. The rate of wear loss was high for $1 \mathrm{wt}$. \% of SiCp at $20 \mathrm{~N}$ normal loads and it was low for $2 \mathrm{wt} . \%$ of SiCp at $10 \mathrm{~N}$ normal loads up to $3000 \mathrm{~m}$ sliding distance in steps of $250 \mathrm{~m}$. The wear loss was nonlinear and the minimum was at $1 \mathrm{~m} / \mathrm{s}$ sliding velocity, in between $500 \mathrm{~m}$ and $1500 \mathrm{~m}$ sliding distance as shown in Figure 9(a). This was due to formation of oxide layer on the nanocomposite surface during sliding action against the steel disc surface at a 1 $\mathrm{m} / \mathrm{s}$ sliding velocity, from $500 \mathrm{~m}$ to $1500 \mathrm{~m}$ sliding distance. The wear loss increased from $2000 \mathrm{~m}$ to $3000 \mathrm{~m}$ sliding distance at different normal loads at $1 \mathrm{~m} / \mathrm{s}$ sliding velocity. The wear loss at $1.5 \mathrm{~m} / \mathrm{s}$ sliding velocity in steps of $250 \mathrm{~m}$ at various normal loads is represented in Figure 9(b).
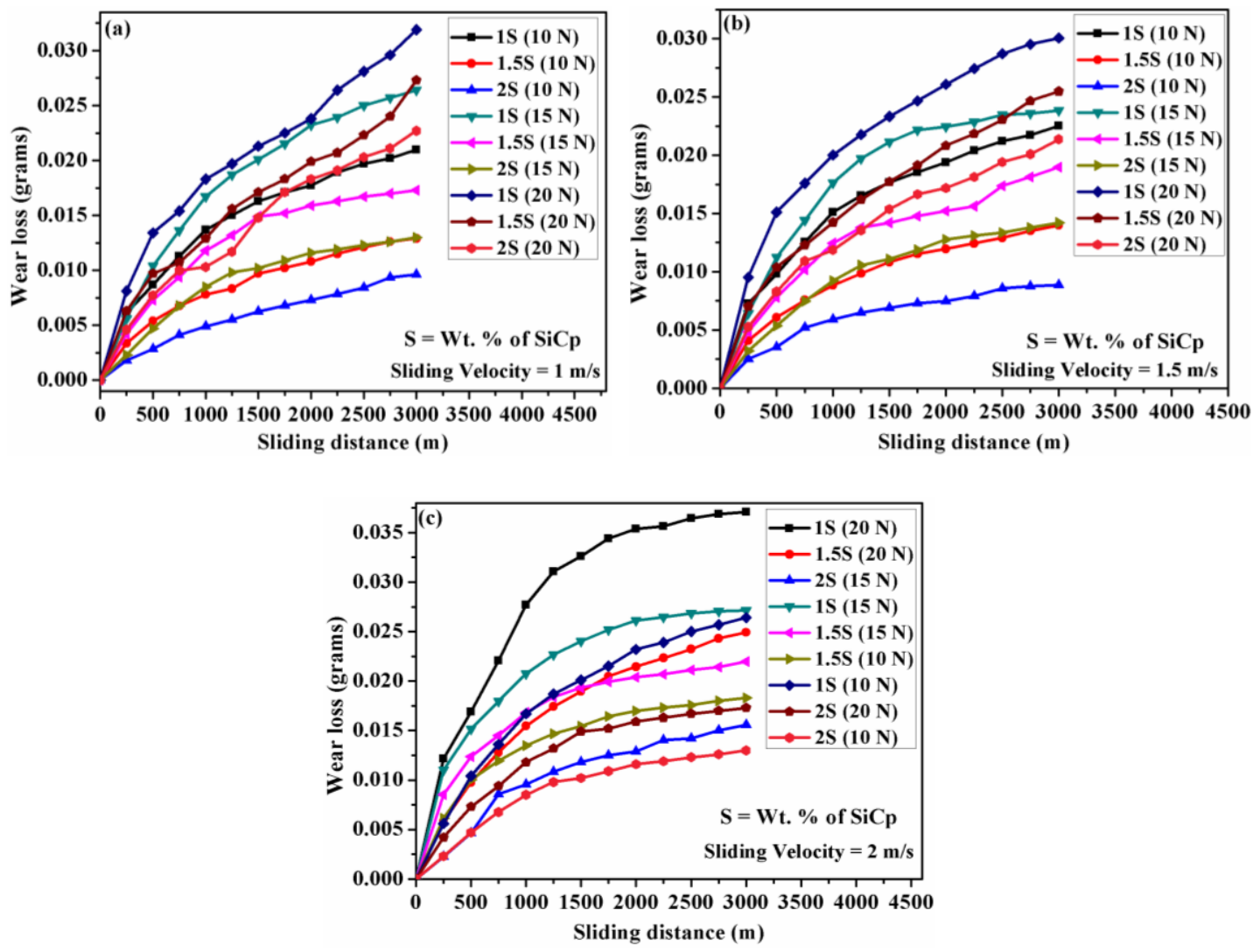

Figure 9. AA6061/SiCp nanocomposites with respect to sliding distance at different conditions.

The wear loss was almost linear up to $1750 \mathrm{~m}$ and nonlinear in between $1750 \mathrm{~m}$ to $2500 \mathrm{~m}$ sliding distances. The oxidation rate increased with increasing the sliding velocity as a function of sliding distance. This may be because of the rise in interface temperature which softened the nanocomposites $[35,36]$. The wear loss at sliding velocity of $2 \mathrm{~m} / \mathrm{s}$ in steps of $250 \mathrm{~m}$ at various normal loads on the pin is plotted in Figure 9(c). The nanocomposites wear loss was almost linear up to $500 \mathrm{~m}$ and nonlinear in between 500 $\mathrm{m}$ to $1000 \mathrm{~m}$ and $2000 \mathrm{~m}$ to $2500 \mathrm{~m}$ sliding distances. The formation of oxides with respect to sliding distance at higher sliding velocities increased. This led to nonlinear wear loss due to the hard asperities in between the pin surface and steel disc. 


\section{Effect of Sliding Velocity on Wear Loss}

Wear loss in the nanocomposites with respect to sliding velocity is represented in Figure 10. The wear loss was increased with increasing sliding velocity as a function of reinforcements in the matrix. The wear loss was high at $2 \mathrm{~m} / \mathrm{s}$ sliding velocity for $1 \mathrm{wt}$. \% of $\mathrm{SiCp}$ reinforced nanocomposites at $10 \mathrm{~N}$ normal loads. The wear loss of the nanocomposites was the minimum at $1 \mathrm{~m} / \mathrm{s}$ sliding velocity for $2 \mathrm{wt}$. \% of SiCp reinforced nanocomposites at $10 \mathrm{~N}$ normal loads. The change in wear loss linearly varied in between 1 and $1.5 \mathrm{~m} / \mathrm{s}$ sliding velocities for all three normal load conditions. The change in wear loss was high for 1 and $1.5 \mathrm{wt}$. \% of SiCp reinforced nanocomposites in between 1.5 to 2 $\mathrm{m} / \mathrm{s}$ sliding velocities and low for the remaining conditions. The increase in wear loss can be mainly attributed to the destruction of the mechanically mixed layer (MML) formed and material softening due to the increased temperature with increased sliding velocity. Furthermore, increase in wear loss at higher sliding velocity was due to increased strain rate in deformed subsurface [37].

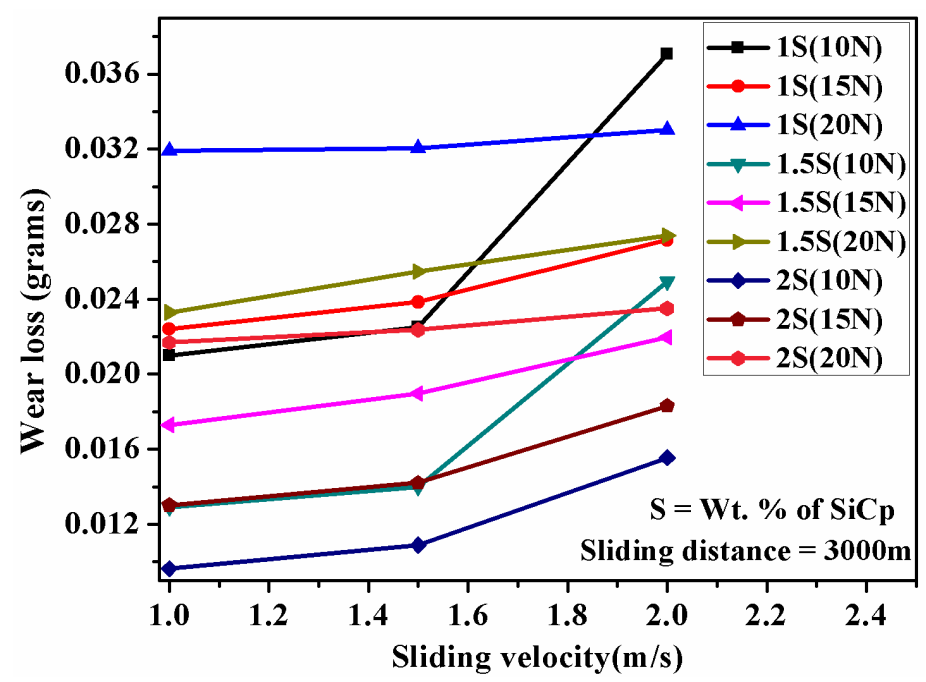

Figure 10. AA6061/SiCp nanocomposites wear loss with varying sliding velocities.

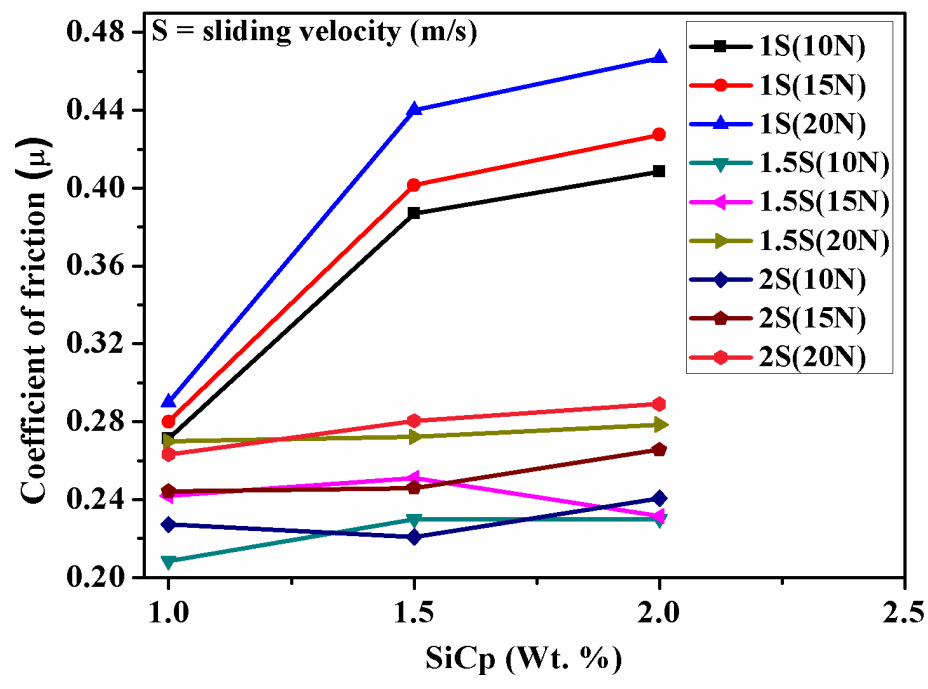

Figure 11. Variation in the friction coefficient of AA6061/SiCp nanocomposites with varying weight percentage of $\mathrm{SiCp}$. 


\section{Effect of SiCp Weight Percentage on Coefficient of Friction}

The variation of the friction coefficient of the nanocomposites as a function of wt. \% of SiCp at sliding distance of $3000 \mathrm{~m}$ with different sliding velocities and normal loads is shown in Figure 11. The friction coefficient changed linearly for all conditions as a function of normal loads on pin material. The friction coefficient increased with increasing the addition of the SiCp reinforcements in the matrix material. The cubic structured beta silicon carbide particles in nanocomposite were attributed to rise in the friction coefficient and which was more with increasing the reinforcement weight percentage in the matrix [33].

\section{Effect of normal load on coefficient of friction}

The friction coefficient of the nanocomposites with varying normal loads on the pin is plotted in Figure 12. The coefficient of friction increased with increasing the normal loads on the pin and decreased at higher sliding velocities. The friction coefficient varied largely in between 10 and $15 \mathrm{~N}$ with small increments in between 15 and $20 \mathrm{~N}$ normal loads on pin material. The coefficient of friction decreased from 10 to $15 \mathrm{~N}$ normal loads and increased from 15 to $20 \mathrm{~N}$ normal loads on pin material for $2 \mathrm{wt}$ \% of SiCp at sliding velocity of $1.5 \mathrm{~m} / \mathrm{s}$. The obtained experimental results were attributed to the rise of the coefficient of friction of the nanocomposites due to the increases in the depth of indentation of the asperities into the nanocomposite surfaces which caused increase in tangential normal loads on the nanocomposite material [23].

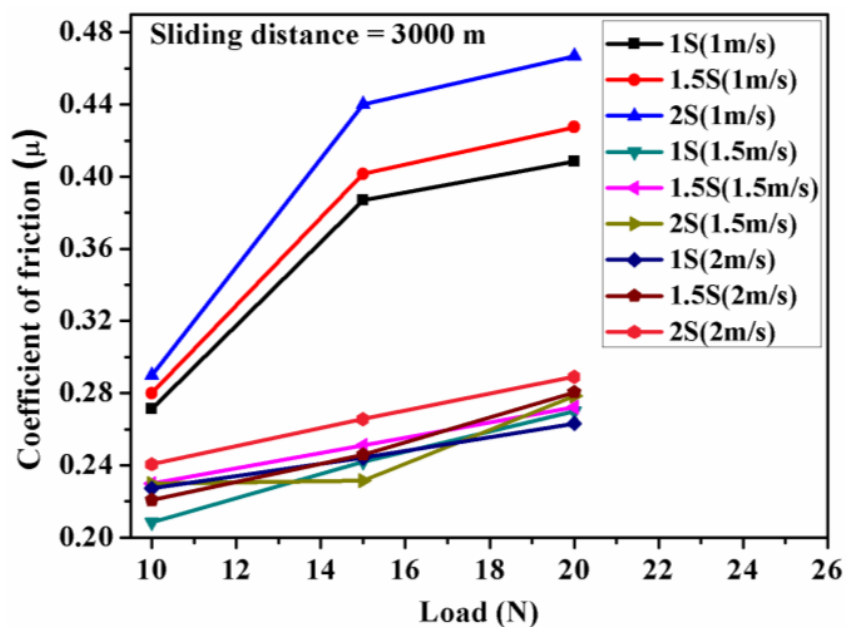

Figure 12. Variation of friction coefficient of the AA6061/SiCp nanocomposites with varying normal loads.

\section{Effect of sliding distance on coefficient of friction}

The friction coefficient of the AA6061/SiCp nanocomposites with varying sliding distances at various sliding velocities and at different normal loads on pin material is shown in Figure 13. The results revealed that the friction coefficient continuously reduced with increasing the sliding distance in steps of $250 \mathrm{~m}$. Figure 13(a) shows the high friction coefficient at sliding velocity of $1 \mathrm{~m} / \mathrm{s}$ for $2 \mathrm{wt}$. \% of SiCp at $20 \mathrm{~N}$ normal loads and the low coefficient of friction was observed at $1 \mathrm{wt}$. \% of SiCp at $10 \mathrm{~N}$ normal loads at a sliding distance in steps of $250 \mathrm{~m}$. The coefficient of friction is nonlinear at sliding velocity of $1 \mathrm{~m} / \mathrm{s}$, and sliding distance in between $500 \mathrm{~m}$ and $1500 \mathrm{~m}$. The variation in coefficient of friction was minimum at these conditions. This was due to the formation of 
the oxide layer on the pin surface during sliding action of the nanocomposites against the steel disc surface at $1 \mathrm{~m} / \mathrm{s}$ sliding velocity, from 500 to $1500 \mathrm{~m}$ sliding distance. The coefficient of friction decreased linearly from 2000 to $3000 \mathrm{~m}$ sliding distance for all the normal loads at a sliding velocity of $1 \mathrm{~m} / \mathrm{s}$.
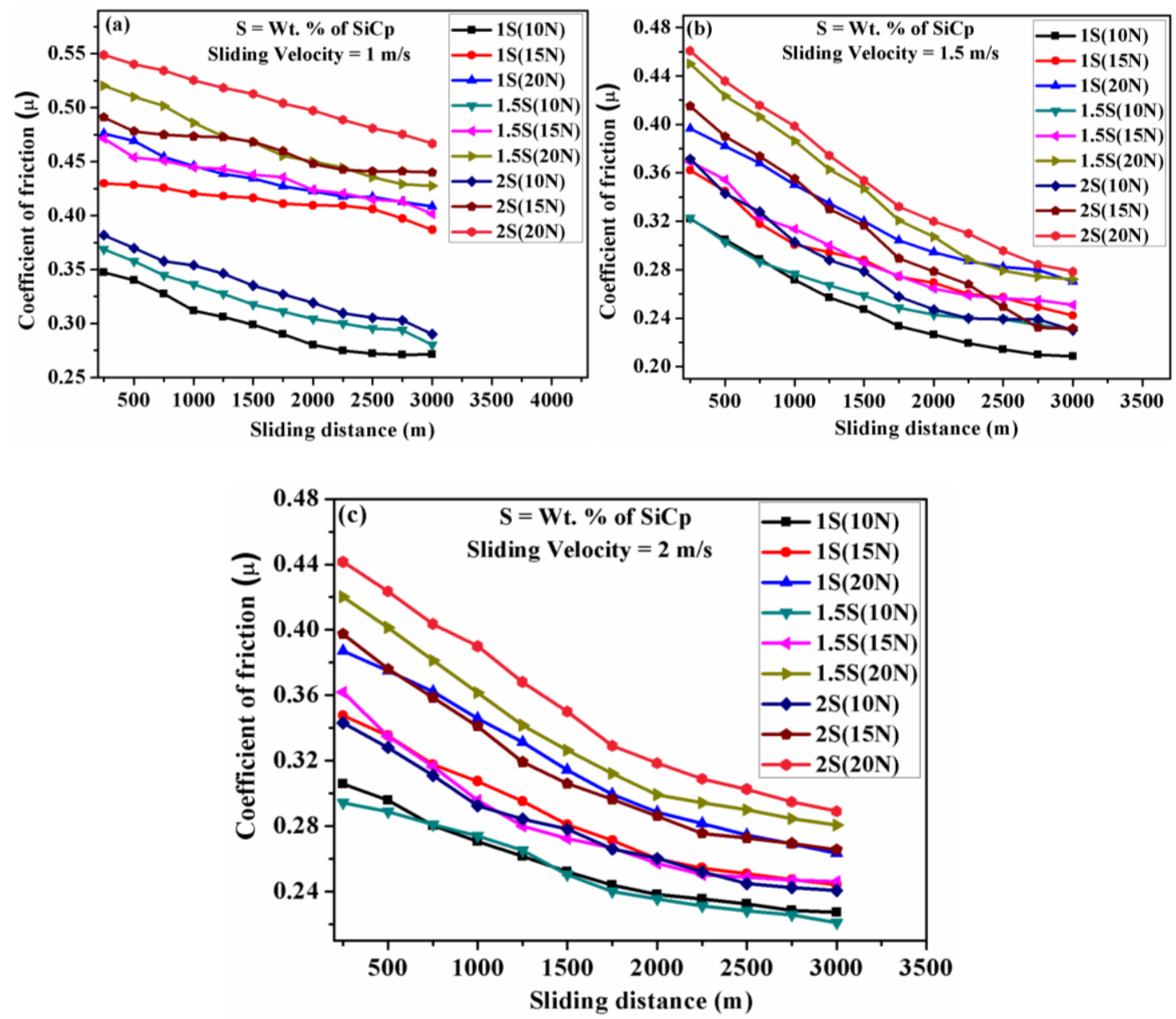

Figure 13. Friction coefficient of AA6061/SiCp nanocomposites with varying sliding distances.

The coefficient of friction decreased nonlinearly from sliding distance 2000 to $3000 \mathrm{~m}$ for $1.5 \mathrm{wt}$. \% of SiCp at 10, $15 \mathrm{~N}$ normal loads, and $2 \mathrm{wt} . \%$ of SiCp at 10, 15, and $20 \mathrm{~N}$ normal loads. The coefficient of friction at $1.5 \mathrm{~m} / \mathrm{s}$ sliding velocity with varying sliding distance in steps of $250 \mathrm{~m}$ at different normal loads is shown in Figure 13(b). The coefficient of friction was linear up to $1500 \mathrm{~m}$ and nonlinear in between $1500 \mathrm{~m}$ to 2500 $\mathrm{m}$ sliding distance. This may be attributed to the higher oxidation rate of softened nanocomposites pin surface at high interface temperature with the sliding velocity and the sliding distance [32]. The friction coefficient at $2 \mathrm{~m} / \mathrm{s}$ sliding velocity in steps of 250 $\mathrm{m}$ sliding distances at various normal loads on the pin is presented in Figure 13(c). The friction coefficient was linear up to $500 \mathrm{~m}$ and nonlinear in between $500 \mathrm{~m}$ to $1500 \mathrm{~m}$ sliding distances. The formation of oxides with respect to the sliding distance at higher sliding velocities increased. This led to a nonlinear friction coefficient due to the hard asperities in between the composite pin surface and steel disc. 


\section{Effect of Sliding Velocity on Coefficient of Friction}

The variations in the friction coefficient of the nanocomposites with varying sliding velocity at different wt. \% of SiCp reinforcements, various applied normal loads and at $3000 \mathrm{~m}$ sliding distance are represented in Figure 14. The coefficient of friction decreased linearly in between 1 and $1.5 \mathrm{~m} / \mathrm{s}$ sliding velocities and slightly increased from 1.5 to 2 $\mathrm{m} / \mathrm{s}$ sliding velocity for all conditions. The change in the friction coefficient was due to the irregular contact between nanocomposite pin material and steel disc. The coefficient of friction was high at sliding velocity $1 \mathrm{~m} / \mathrm{s}$ for $2 \mathrm{wt}$. \% of SiCp reinforced nanocomposites at $20 \mathrm{~N}$ normal loads on the pin and low at sliding velocity $1.5 \mathrm{~m} / \mathrm{s}$ for 1 wt. \% of SiCp reinforced nanocomposites at $10 \mathrm{~N}$ normal loads on pin material. The average coefficient of friction at sliding velocity of $1 \mathrm{~m} / \mathrm{s}$ for $1 \mathrm{wt}$. \% of SiCp, $1.5 \mathrm{wt}$ \% of $\mathrm{SiCp}$, and $2 \mathrm{wt}$. \% of SiCp reinforced nanocomposites at a sliding distance $3000 \mathrm{~m}$ and $20 \mathrm{~N}$ normal loads were $0.29,0.43$, and 0.46 , respectively.

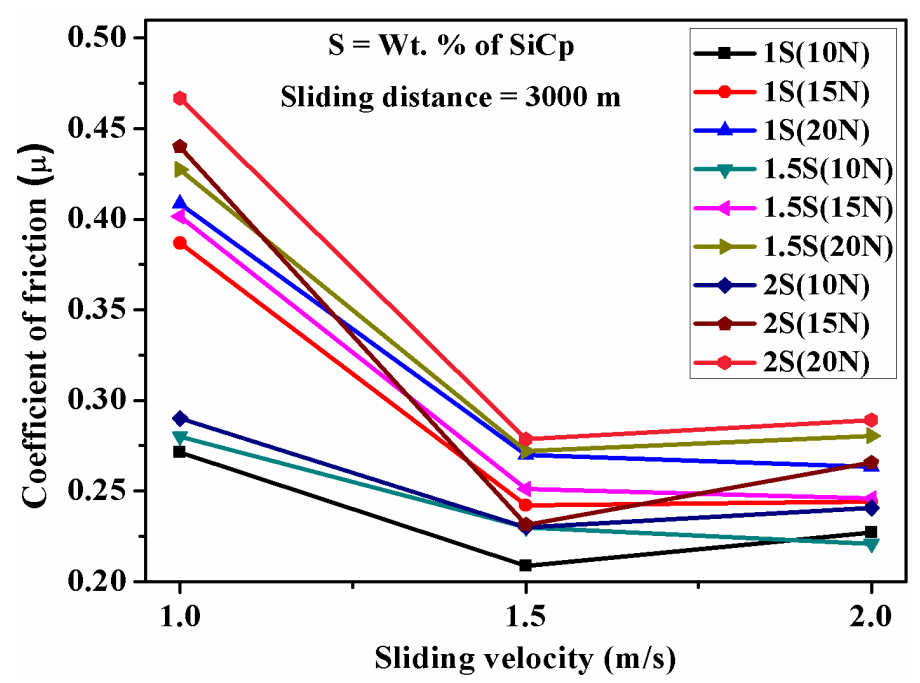

Figure 14. Variation in the friction coefficient of the AA6061/SiCp nanocomposites with different sliding velocities.

The average coefficient of friction at $1.5 \mathrm{~m} / \mathrm{s}$ sliding velocity for $1 \mathrm{wt} . \%$ of $\mathrm{SiCp}$, 1.5 wt. $\%$ of SiCp, and 2 wt. \% of SiCp reinforced nanocomposites at a sliding distance $3000 \mathrm{~m}$, at $20 \mathrm{~N}$ normal loads were $0.26,0.27$, and 0.29 , respectively. The average friction coefficient at sliding velocity $2 \mathrm{~m} / \mathrm{s}$ for $1 \mathrm{wt}$. \% of SiCp, $1.5 \mathrm{wt}$. \% of SiCp, and 2 wt. \% of $\mathrm{SiCp}$ reinforced nanocomposites at sliding distance $3000 \mathrm{~m}$, at $20 \mathrm{~N}$ normal loads were $0.26,0.27$, and 0.28 , respectively. The lower friction coefficient was obtained at a large amount of sliding velocities and at higher sliding distances [38]. The variation of the friction coefficient was low because of the formation of the oxide layer on the worn surfaces at higher normal loads and sliding velocities [20].

\section{Worn Surface Analysis}

In this study, three types of wear mechanisms were observed during wear testing at dry condition i.e., abrasion, oxidation, and delamination. Figures 15-17 represent the SEM morphology of the AA6061/ SiCp nanocomposites of worn surfaces under different applied loads and different sliding velocities. The worn surfaces of AA6061/SiCp nanocomposites were studied to understand the effect of various process parameters at normal atmospheric dry conditions through the micrographs of SEM. In the SEM images, 
' $G$ ' represents the grooves, ' $D$ ' denotes the delaminating layer and ' $O$ ' is for oxide debris on the nanocomposite worn surface. The worn surfaces revealed that the abrasion wear was the dominant wear mechanism at all loads and sliding velocities. The several fine deep grooves, scratches and wear particles were apparent parallel to the sliding direction of the nanocomposites pin.

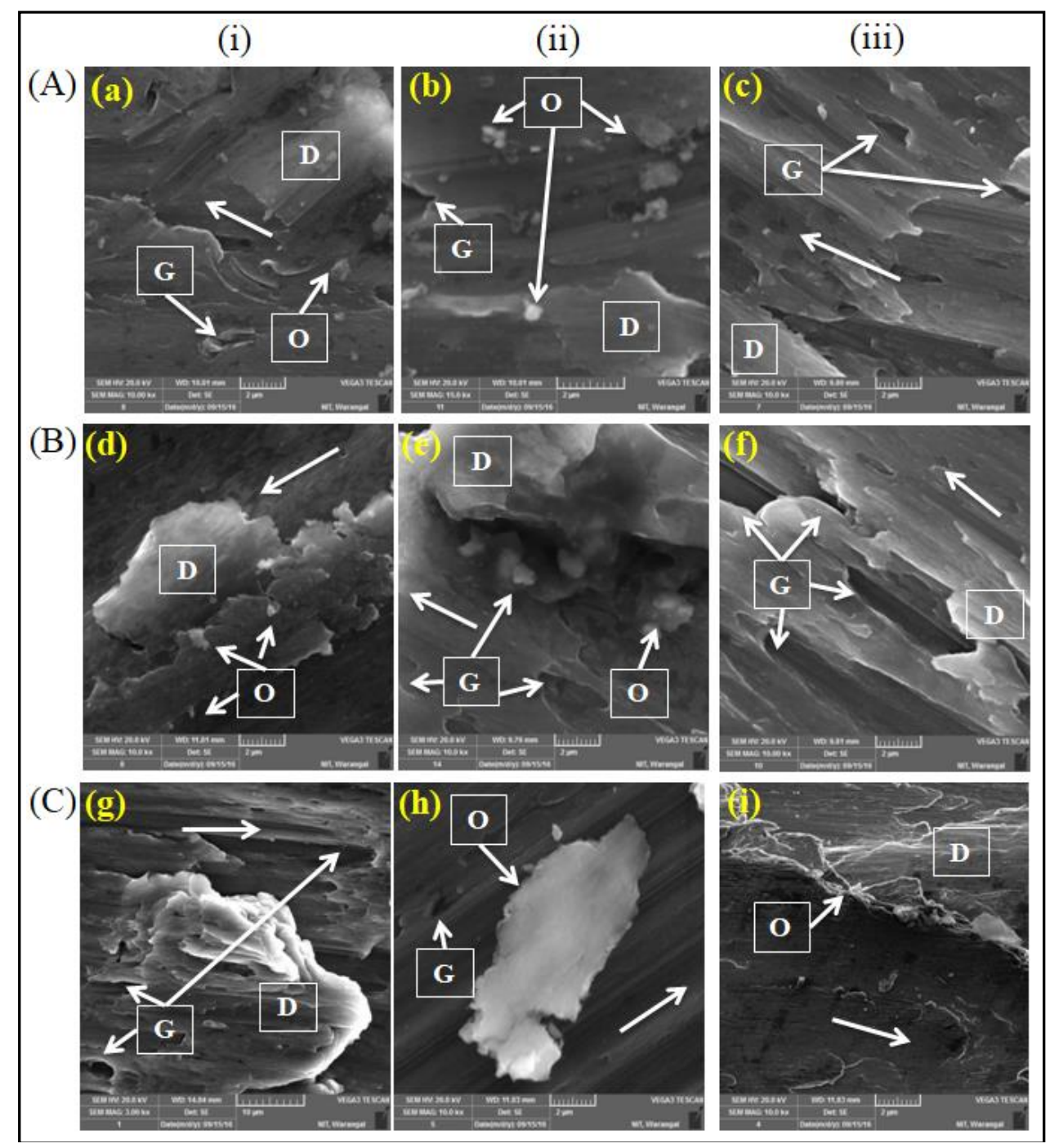

Figure 15. AA6061/1 wt. \% of SiCp nanocomposites worn surfaces at various sliding velocities (i) $10 \mathrm{~N}$; (ii) $15 \mathrm{~N}$; (iii) $20 \mathrm{~N}$; (A) $1 \mathrm{~m} / \mathrm{s}$; (B) $1.5 \mathrm{~m} / \mathrm{s}$; (C) $2 \mathrm{~m} / \mathrm{s}$.

The worn surfaces of AA6061/1 wt. \% SiCp nanocomposites at various sliding velocities and loads are shown in Figure 15. The hard particles of the disc counter face cut and penetrated into the nanocomposite pin, causing the wear by removing the small chips of the nanocomposites material; the typical characteristics were associated with abrasive wear [39]. The worn surfaces of the nanocomposites at $1 \mathrm{~m} / \mathrm{s}$ sliding velocity revealed the fine grooves, delaminating layer and oxide debris in the sliding direction for all loads at $3000 \mathrm{~m}$ sliding distance. At $1.5 \mathrm{~m} / \mathrm{s}$ sliding velocity the worn surfaces of the nanocomposites were changed to shallower scratches with the increase of normal loads on pin material from $10 \mathrm{~N}$ to $20 \mathrm{~N}$. The formation of shallower scratches on the worn surface was due to the plastic flow of the nanocomposite material at a higher sliding 
velocity. The worn surface of the nanocomposite at a sliding velocity of $2 \mathrm{~m} / \mathrm{s}$ revealed the circular grooves and shallower scratches at normal load of $10 \mathrm{~N}$ (Figure $15(\mathrm{~g})$ ). Figure 15(h) shows clearly the presence of larger oxide debris on the worn surface of the nanocomposites at applied normal loads of 15 N. In Figure 15(i), it was observed that the oxidation was the dominant wear mechanism at higher applied normal loads of $20 \mathrm{~N}$ on the pin. The oxide film present on the already worn surface of the nanocomposite introduced the frictional heat during contact of the disc material [40]. This frictional heat obviously affected the wear loss of the nanocomposite. However, the development of grooves, oxide debris and plastic deformation of the nanocomposite pin in the direction of sliding depended on the normal loads and sliding velocities. The increase of normal loads on the pin at the constant sliding velocity converted the fine grooves into shallower scratches. The increase of sliding velocity at constant normal loads on pin forced the fine grooves into circular scratches on the already worn surface of the nanocomposites.

The worn surfaces of the AA6061/1.5 wt. \% of SiCp nanocomposites are shown in Figure 16. It was observed that the abrasive wear mechanism was exhibited by the worn surfaces. The worn surfaces of the nanocomposites at $1 \mathrm{~m} / \mathrm{s}$ sliding velocity revealed that delaminating layer and oxide debris were in the sliding direction. The depth of indentation of steel disc material into the pin and formation of shallower deep grooves was higher at $20 \mathrm{~N}$ normal loads for all sliding velocities. The plastic deformation was increased with the rise of applied normal loads on the pin material. Figures $16(\mathrm{a}-\mathrm{c})$ reveal that the oxide debris was increased with increasing the applied normal loads on the nanocomposite pin material at sliding velocity of $1 \mathrm{~m} / \mathrm{s}$. It was identified that the oxide debris particle size was increased with the increasing applied normal loads on nanocomposite pin. The shallower scratches were observed at $1.5 \mathrm{~m} / \mathrm{s}$ sliding velocity and $10 \mathrm{~N}$ applied normal loads (Figure 16(d)). The circular scratches were found at $15 \mathrm{~N}$ normal loads (Figure 16(e)) and similarly at $20 \mathrm{~N}$ normal loads, the shallower scratches were identified with the higher depth of penetration on the worn surfaces (Figure 16(f)). The worn surface of the nanocomposites at $2 \mathrm{~m} / \mathrm{s}$ sliding velocity and $10 \mathrm{~N}$ applied normal loads on nanocomposite pin revealed shallower scratches with a higher depth of penetration and medium size of oxide debris (Figure 16(g)). From Figure 16 (h), it was observed that there were larger size oxide debris at normal loads of 15 N. Figure 16(i) shows the worn surface with higher amount of penetration with severe plastic deformation at $20 \mathrm{~N}$ normal loads.

The SEM micrographs of the AA6061/2 wt. \% SiCp nanocomposites are presented in Figure 17. The wear mechanism observed from the worn surfaces was abrasive wear. The wear surfaces of the nanocomposites at $1 \mathrm{~m} / \mathrm{s}$ sliding velocity revealed that delaminating layer and oxide debris were in the sliding direction (Figure 17 (a)-(c)). From Figures 17 (b), \& (c) it was observed that the depth of penetration of hard material of disc into the pin was higher at $15 \mathrm{~N}$ and $20 \mathrm{~N}$ normal loads and there were shallower deep grooves at $20 \mathrm{~N}$ normal loads on pin material on the nanocomposite wear surface. 


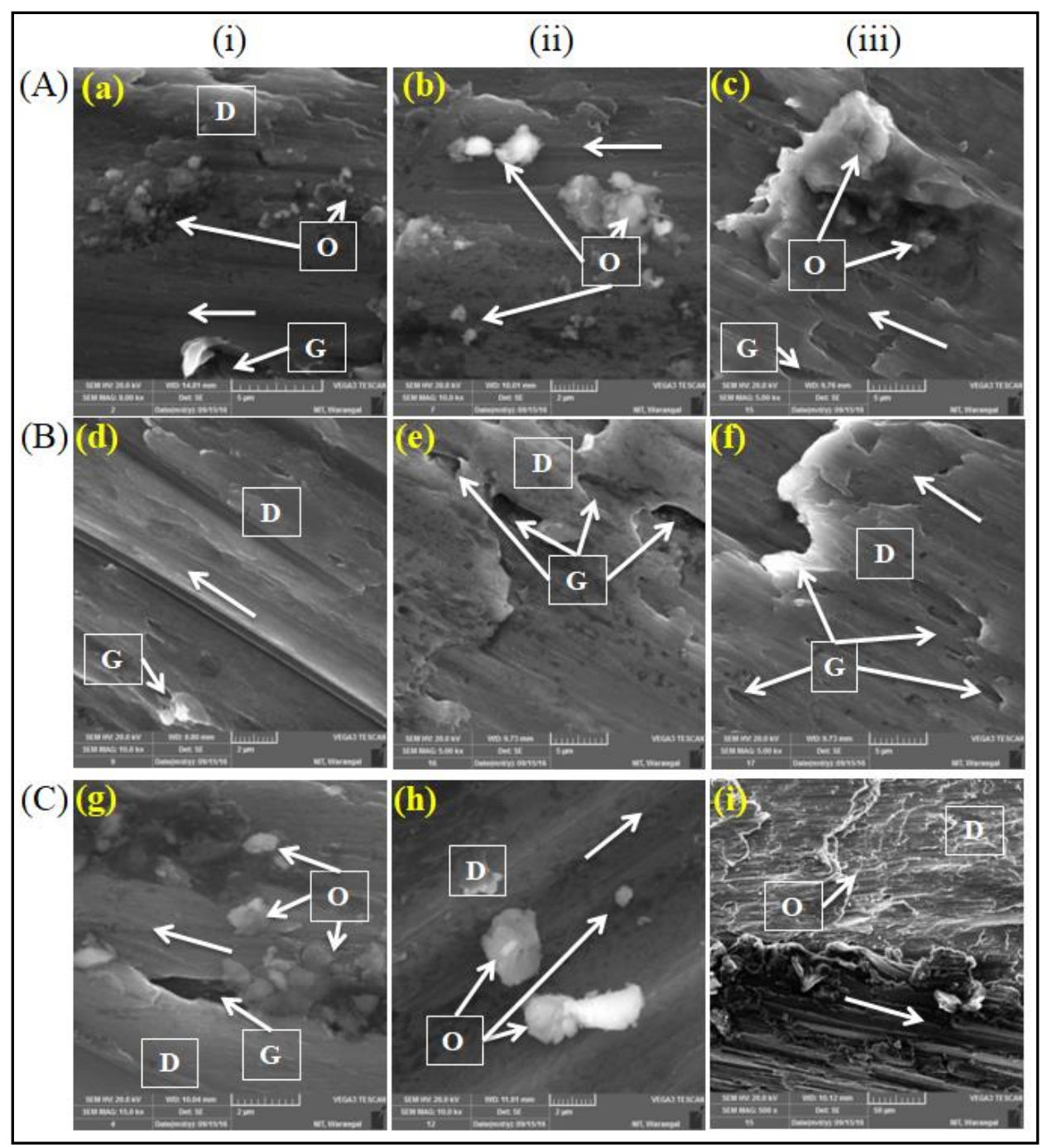

Figure 16. AA6061/1.5 wt. \% of SiCp nanocomposites worn surfaces at various sliding velocities (i) $10 \mathrm{~N}$; (ii) $15 \mathrm{~N}$; (iii) $20 \mathrm{~N}$; (A) $1 \mathrm{~m} / \mathrm{s}$; (B) $1.5 \mathrm{~m} / \mathrm{s}$; (C) $2 \mathrm{~m} / \mathrm{s}$.

The plastic flow was increased with the rise in applied normal loads on the nanocomposite pin. The circular scratches were identified at $1.5 \mathrm{~m} / \mathrm{s}$ sliding velocity and $10 \mathrm{~N}$ normal loads as shown in Figure 17(d). The formation of circular scratches on the wear surfaces was due to the plastic flow of the nanocomposites at higher sliding velocity of the disc. At $20 \mathrm{~N}$ normal loads, the bigger size oxide debris was found on the worn surface as shown in Figures 17(f) and (i). The worn surface of the nanocomposites at sliding velocity of $2 \mathrm{~m} / \mathrm{s}$ revealed large size oxide debris at normal load of $10 \mathrm{~N}$ (Figure 17(g)). The formation of oxide debris particles on the worn surfaces was increased with the rise of normal loads on the pin which is shown in Figures 17(h) and (i). However, the deformation and development of oxide debris on the nanocomposite worn surfaces were decreased with the increase of $\mathrm{SiCp}$ reinforcement particles. The depth of penetration of hard disc material on the worn surfaces was increased with increasing the applied normal loads on pin and decreased with increasing the SiCp reinforcement particles. The oxide debris size also increased with increasing the applied normal loads on the nanocomposite pins. 
(i)

(A)

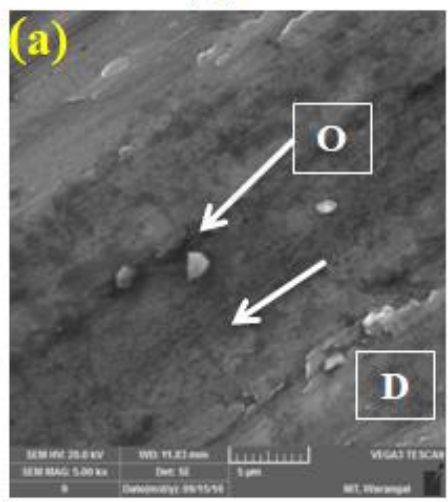

(B)

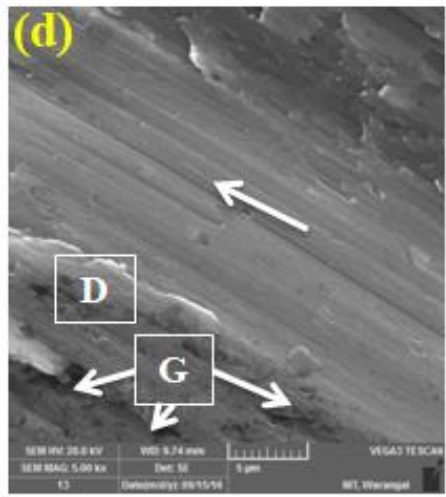

(C)

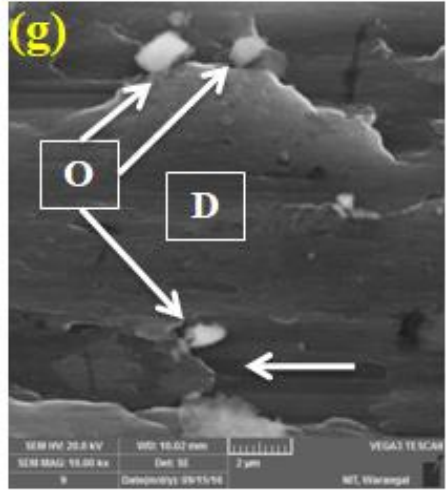

(ii)
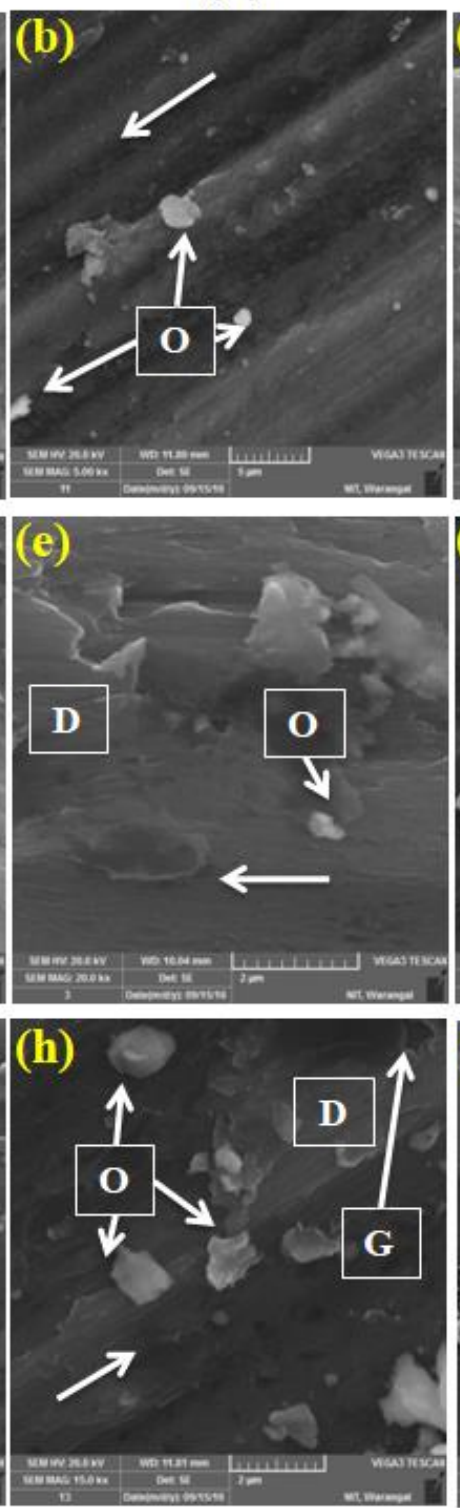

(iii)
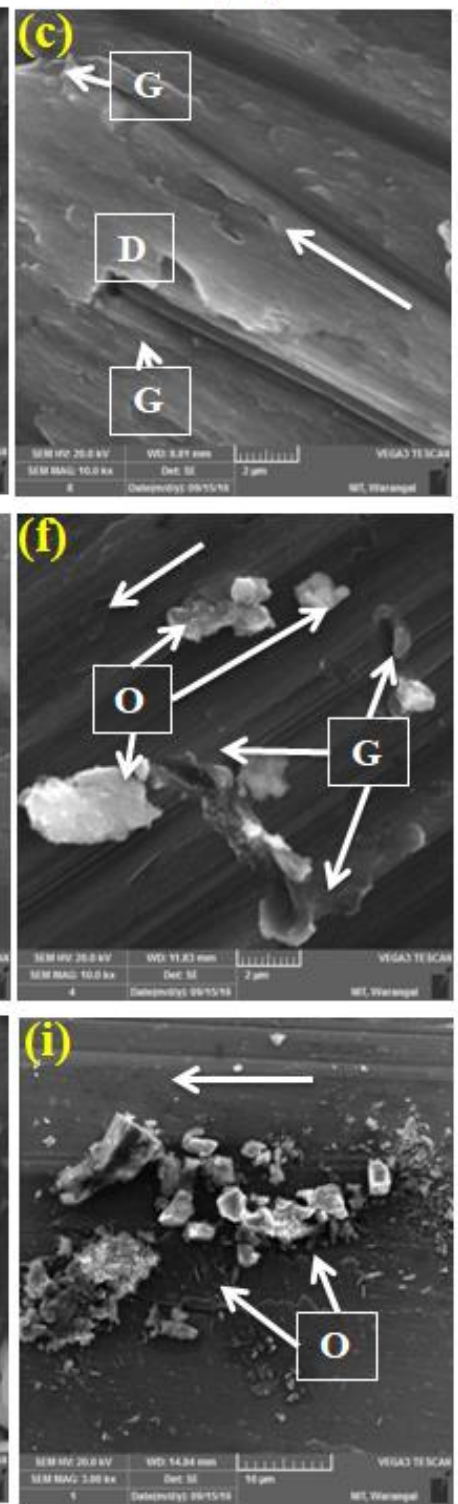

Figure 17. AA6061/2 wt. \% of SiCp nanocomposites worn surfaces at various sliding velocities (i) $10 \mathrm{~N}$; (ii) $15 \mathrm{~N}$; (iii) $20 \mathrm{~N}$; (A) $1 \mathrm{~m} / \mathrm{s}$; (B) $1.5 \mathrm{~m} / \mathrm{s}$; (C) $2 \mathrm{~m} / \mathrm{s}$.

The wear mechanisms of the AA6061/SiCp nanocomposites were defined by sliding velocity and normal loads. In the present test conditions, various groups of mechanisms were found to be gradual and the boundaries on the diagram were approximate (Figure 18). At the lower sliding velocity and lower normal loads, fine grooves were identified with oxidation, abrasion, and delamination wear mechanisms. At $15 \mathrm{~N}$ normal loads, with higher sliding velocities, the circular scratches were identified with oxidation, delamination, and abrasion wear mechanisms. At $20 \mathrm{~N}$ normal loads, with lower sliding velocities, the smaller deep grooves were found with delamination and abrasion. At $20 \mathrm{~N}$ normal loads with higher sliding velocities, the larger size oxide debris with soften surfaces were identified, with delamination and abrasion wear mechanism. 


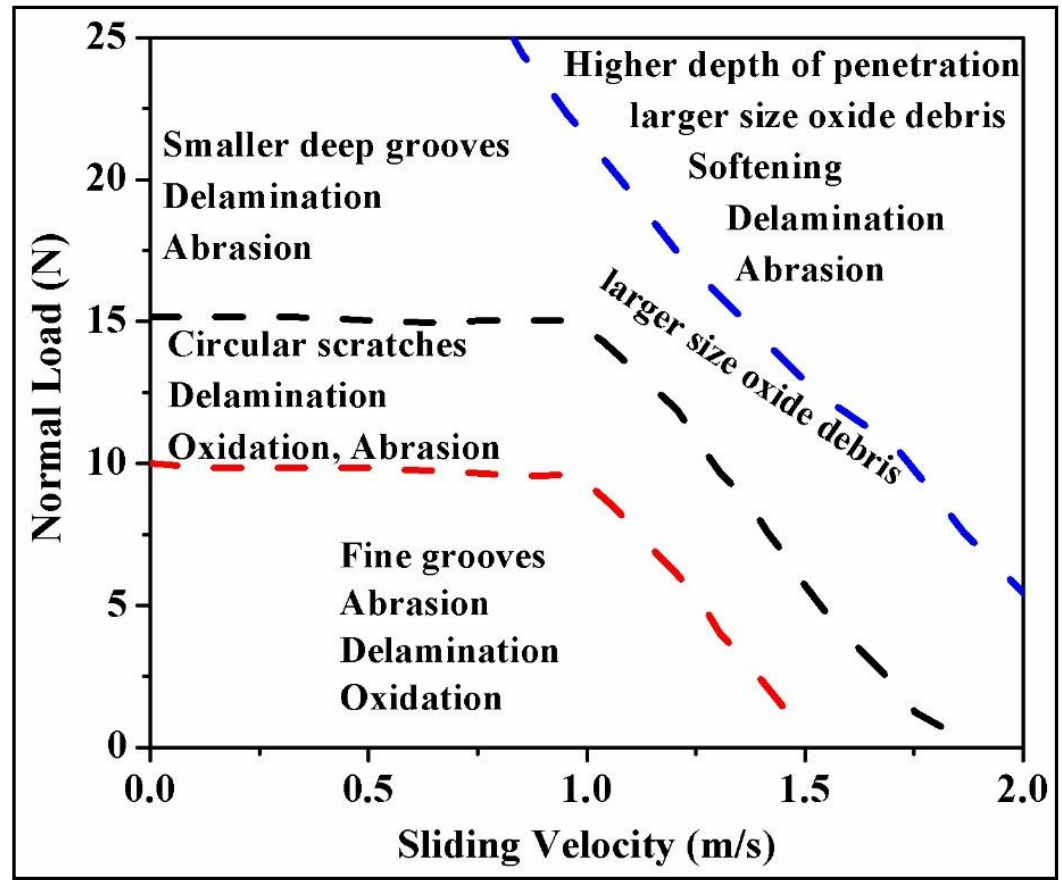

Figure 18. Wear mechanisms of the AA6061/SiCp nanocomposites are drawn at various conditions and with approximate boundaries in the present study.

\section{EDX spectrum analysis}

The wear surfaces of the nanocomposites at $20 \mathrm{~N}$ normal loads, $2 \mathrm{~m} / \mathrm{s}$ sliding velocity, and $3000 \mathrm{~m}$ sliding distance were analysed by using EDX spectrum. EDX results of the nanocomposites revealed that the intensity of peak was oxygen. It indicated that the oxide debris development was there on the worn surface at dry sliding conditions. During dry sliding of the nanocomposites on the hard steel disc (EN31) counter surface, heat was generated due to the friction which led to the rise of temperature [37]. The combination of temperature rise and environmental reaction caused the formation of the oxide debris at pin and disc contact surfaces [41]. The EDX spectrum analysis of the worn surface of the AA6061/1 wt. \% SiCp nanocomposites at $20 \mathrm{~N}$ normal loads and sliding velocity of $2 \mathrm{~m} / \mathrm{s}$ is represented in Figure 19(a). The results revealed that the small intensity of silicon, carbon peaks and a strong intensity of aluminium peak were present. It designated the plastic flow of AA6061/1 wt. \% SiCp nanocomposites at dry sliding conditions. The EDX spectrum analysis of the worn surface of AA6061/ 1.5 wt. \% SiCp at normal load of 20 $\mathrm{N}$ and $2 \mathrm{~m} / \mathrm{s}$ sliding velocity is presented in Figure 19(b). The low intensity of the carbon peak and average intensity of silicon peak specified that SiCp reinforcement particles were dragged from the AA6061 alloy matrix. The EDX spectrum analysis of the worn surface of the AA6061/2 wt. \% SiCp nanocomposites at applied normal loads of $20 \mathrm{~N}$ and $2 \mathrm{~m} / \mathrm{s}$ sliding velocity is represented in Figure 19 (c). The strong intensity of carbon, aluminium and silicon peaks were observed. However, the noticeable iron and oxygen peaks were also observed. The hard disc counter surface was eroded by the SiCp reinforcements. The oxygen and iron appeared in the EDX, indicating the development of iron oxides on the worn surface of the contact parts. Because of the heat generation between the mating parts, the temperature was raised and caused the formation of oxide film on the mating surfaces [40]. 
(a)

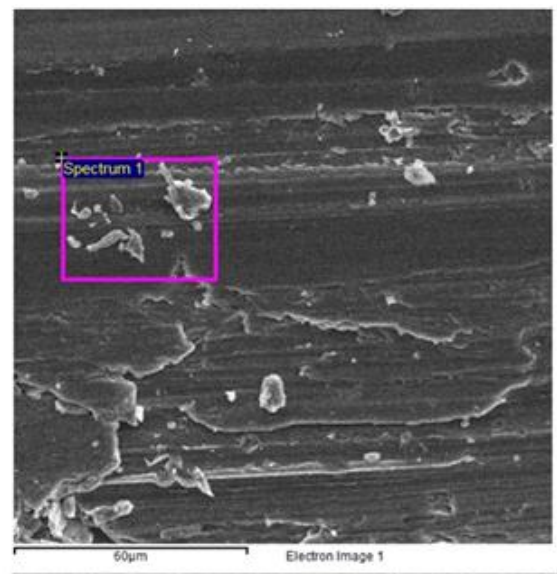

(b)

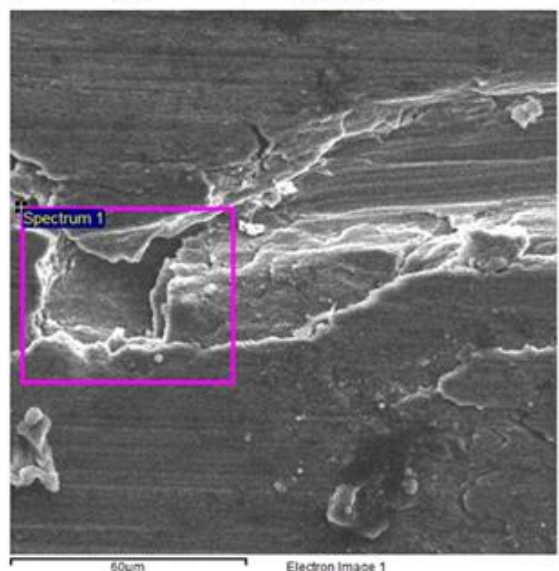

(c)
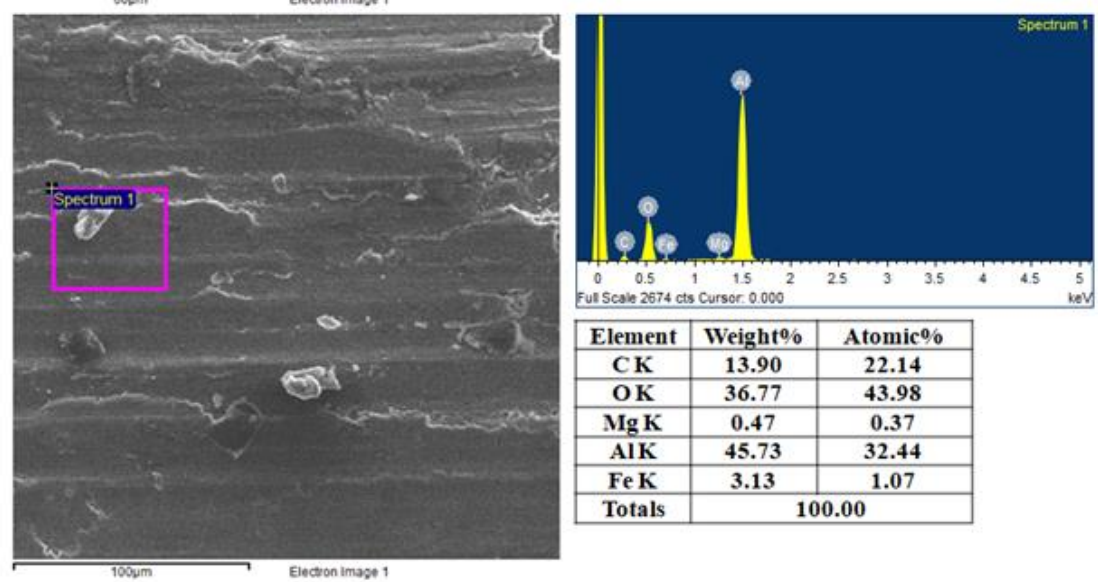

\begin{tabular}{|c|c|c|}
\hline Element & Veight $\%$ & Atomic $\%$ \\
\hline CK & 13.90 & 22.14 \\
\hline OK & 36.77 & 43.98 \\
\hline Mg K & 0.47 & 0.37 \\
\hline AlK & 45.73 & 32.44 \\
\hline Fe K & 3.13 & 1.07 \\
\hline Totals & \multicolumn{2}{|c|}{100.00} \\
\hline
\end{tabular}

Figure 19. EDX of wear surfaces of AA6061/SiCp nanocomposites at applied normal loads $20 \mathrm{~N}$ at $2 \mathrm{~m} / \mathrm{s}$ sliding speed (a) $1 \mathrm{wt}$. \%; (b) $1.5 \mathrm{wt}$ \%; (c) 2 wt. $\%$.

\section{CONCLUSIONS}

In this study, AA6061/ $\operatorname{SiCp}(1,1.5$, and 2 wt. \%) of nanocomposites were fabricated successfully using the ultrasonic assisted casting. The nanocomposites exhibited better wear resistance and friction coefficient with increasing SiCp reinforcement content. The average coefficient of friction at sliding velocity of $1 \mathrm{~m} / \mathrm{s}$ for $1 \mathrm{wt} . \%$ of SiCp, $1.5 \mathrm{wt}$. \% of $\mathrm{SiCp}$, and 2 wt. \% of SiCp reinforced nanocomposites at $3000 \mathrm{~m}$ sliding distance and $20 \mathrm{~N}$ normal loads were $0.29,0.43$, and 0.46 , respectively. The average coefficient of friction at $1.5 \mathrm{~m} / \mathrm{s}$ sliding velocity for $1 \mathrm{wt}$. $\%$ of SiCp, $1.5 \mathrm{wt}$. $\%$ of $\mathrm{SiCp}$, and $2 \mathrm{wt}$. \% of 
SiCp reinforced nanocomposites at maximum load and high sliding distance were 0.26 , 0.27 , and 0.29 , respectively. The average friction coefficient at sliding velocity of $2 \mathrm{~m} / \mathrm{s}$ for 1 wt. \% of SiCp, $1.5 \mathrm{wt}$. \% of $\mathrm{SiCp}$, and $2 \mathrm{wt}$. \% of SiCp reinforced nanocomposites at maximum load and maximum sliding distance were $0.26,0.27$, and 0.28 , respectively. The friction coefficient was minimised with the increment of sliding distance and sliding velocity for all applied normal load conditions. Higher sliding velocities and sliding distances lowered the friction coefficient. The rise of SiCp reinforcements in the matrix increased the coefficient of friction due to its cubic structure.

Worn surfaces of the nanocomposites exhibited the abrasion, oxidation, and delamination wear mechanisms. At lower sliding velocity and lower normal loads, fine grooves were identified with oxidation, abrasion, and delamination wear mechanisms. At $15 \mathrm{~N}$ normal loads and high sliding velocities, the circular scratches were identified with oxidation, delamination, and abrasion wear mechanisms. At $20 \mathrm{~N}$ normal loads and lower sliding velocities, the smaller deep grooves were found with delamination and abrasion. At $20 \mathrm{~N}$ normal loads and high sliding velocities, the larger size oxide debris with softened surface were identified with delamination and abrasion wear mechanism. The EDX analysis of the wear surfaces of nanocomposites revealed the noticeable oxygen peak and iron peak indicating the development of iron oxide debris on the wear surface of contact parts.

\section{ACKNOWLEDGEMENTS}

The authors would like to thank the Director NIT Warangal and Department of Mechanical Engineering for their valuable guidance and support in this research work.

\section{REFERENCES}

[1] Reihani SS. Processing of squeeze cast Al6061-30vol\% SiC composites and their characterization. Materials \& Design. 2006;27:216-22.

[2] Jamil W, Aripin M, Sajuri Z, Abdullah S, Omar M, Abdullah M, et al. Mechanical properties and microstructures of steel panels for laminated composites in armoured vehicles. International Journal of Automotive \& Mechanical Engineering. 2016;13.

[3] Rao VR, Ramanaiah N, Rao MS, Sarcar M, Kartheek G. Optimisation of process parameters for minimum volumetric wear rate on AA7075-TiC metal matrix composite. International Journal of Automotive \& Mechanical Engineering. 2016;13.

[4] Mohanty S, Routara B. A review on machining of metal matrix composites using nanoparticle mixed dielectric in electro-discharge machining. International Journal of Automotive \& Mechanical Engineering. 2016;13.

[5] Puvanesan M, Rahman M, Najiha M, Kadirgama K. Experimental investigation of minimum quantity lubrication on tool wear in aluminum alloy 6061-t6 using different cutting tools. International Journal of Automotive and Mechanical Engineering. 2014;9:1538.

[6] Wang Z, Song M, Sun C, He Y. Effects of particle size and distribution on the mechanical properties of $\mathrm{SiC}$ reinforced $\mathrm{Al}-\mathrm{Cu}$ alloy composites. Materials Science and Engineering: A. 2011;528:1131-7.

[7] Cao G, Konishi H, Li X. Mechanical properties and microstructure of SiCreinforced $\mathrm{Mg}-(2,4) \mathrm{Al}-1 \mathrm{Si}$ nanocomposites fabricated by ultrasonic cavitation 
based solidification processing. Materials Science and Engineering: A. 2008;486:357-62.

[8] L P. Abrasive wear behaviour of aluminium hybrid nanocomposites produced by ultrasonication assisted casting method. International Journal of Automotive and Mechanical Engineering. 2017;14:4561-73.

[9] Amouri K, Kazemi S, Momeni A, Kazazi M. Microstructure and mechanical properties of Al-nano/micro $\mathrm{SiC}$ composites produced by stir casting technique. Materials Science and Engineering: A. 2016;674:569-78.

[10] Basavarajappa S, Chandramohan G, Mukund K, Ashwin M, Prabu M. Dry sliding wear behavior of Al 2219/SiCp-Gr hybrid metal matrix composites. Journal of Materials Engineering and Performance. 2006;15:668.

[11] Jeyasimman D, Narayanasamy R, Ponalagusamy R, Anandakrishnan V, Kamaraj $\mathrm{M}$. The effects of various reinforcements on dry sliding wear behaviour of AA 6061 nanocomposites. Materials \& Design. 2014;64:783-93.

[12] Zhou X, Zhu D, Xie Q, Luo F, Zhou W. Friction and wear properties of C/C-SiC braking composites. Ceramics International. 2012;38:2467-73.

[13] Acilar M, Gul F. Effect of the applied load, sliding distance and oxidation on the dry sliding wear behaviour of $\mathrm{Al}-10 \mathrm{Si} / \mathrm{SiCp}$ composites produced by vacuum infiltration technique. Materials \& Design. 2004;25:209-17.

[14] Babu J, Kang C. Nanoindentation behaviour of aluminium based hybrid composites with graphite nanofiber/alumina short fiber. Materials \& Design. 2010;31:4881-5.

[15] Soy U, Ficici F, Demir A. Evaluation of the Taguchi method for wear behavior of Al/SiC/B4C composites. Journal of Composite Materials. 2012;46:851-9.

[16] Jiang L-T, Chen G-Q, He X-d, Min Z, Xiu Z-Y, Fan R-J, et al. Microstructure and tensile properties of $\mathrm{TiB} 2 \mathrm{p} / 6061 \mathrm{Al}$ composites. Transactions of Nonferrous Metals Society of China. 2009;19:s542-s6.

[17] Ray AK, Venkateswarlu K, Chaudhury S, Das S, Kumar BR, Pathak L. Fabrication of TiN reinforced aluminium metal matrix composites through a powder metallurgical route. Materials Science and Engineering: A. 2002;338:1605 .

[18] Jeyasimman D, Sivasankaran S, Sivaprasad K, Narayanasamy R, Kambali R. An investigation of the synthesis, consolidation and mechanical behaviour of $\mathrm{Al} 6061$ nanocomposites reinforced by TiC via mechanical alloying. Materials \& Design. 2014;57:394-404.

[19] Moazami-Goudarzi M, Akhlaghi F. Wear behavior of Al 5252 alloy reinforced with micrometric and nanometric $\mathrm{SiC}$ particles. Tribology International. 2016;102:28-37.

[20] Rao R, Das S, Mondal D, Dixit G. Dry sliding wear behaviour of cast high strength aluminium alloy (Al-Zn-Mg) and hard particle composites. Wear. 2009;267:1688-95.

[21] Rao R, Das S. Effect of matrix alloy and influence of SiC particle on the sliding wear characteristics of aluminium alloy composites. Materials \& Design. 2010;31:1200-7.

[22] Rao R, Das S. Effect of sliding distance on the wear and friction behavior of as cast and heat-treated Al-SiCp composites. Materials \& Design. 2011;32:3051-8.

[23] Hassan AM, Alrashdan A, Hayajneh MT, Mayyas AT. Wear behavior of Al-Mg$\mathrm{Cu}$-based composites containing $\mathrm{SiC}$ particles. Tribology International. 2009;42:1230-8. 
[24] Suresha S, Sridhara B. Effect of silicon carbide particulates on wear resistance of graphitic aluminium matrix composites. Materials \& Design. 2010;31:4470-7.

[25] Mazahery A, Shabani MO. Microstructural and abrasive wear properties of SiC reinforced aluminum-based composite produced by compocasting. Transactions of Nonferrous Metals Society of China. 2013;23:1905-14.

[26] Bathula S, Saravanan M, Dhar A. Nanoindentation and wear characteristics of Al 5083/SiCp nanocomposites synthesized by high energy ball milling and spark plasma sintering. Journal of Materials Science \& Technology. 2012;28:969-75.

[27] Darmiani E, Danaee I, Golozar M, Toroghinejad M, Ashrafi A, Ahmadi A. Reciprocating wear resistance of $\mathrm{Al}-\mathrm{SiC}$ nano-composite fabricated by accumulative roll bonding process. Materials \& Design. 2013;50:497-502.

[28] Rajmohan T, Palanikumar K, Ranganathan S. Evaluation of mechanical and wear properties of hybrid aluminium matrix composites. Transactions of Nonferrous Metals Society of China. 2013;23:2509-17.

[29] Srivastava N, Chaudhari G. Strengthening in Al alloy nano composites fabricated by ultrasound assisted solidification technique. Materials Science and Engineering: A. 2016;651:241-7.

[30] Reddy AP, Krishna PV, Rao RN. Al/SiCNP and Al/SiCNP/X nanocomposites fabrication and properties: A review. Proceedings of the Institution of Mechanical Engineers, Part N: Journal of Nanomaterials, Nanoengineering and Nanosystems. 2017;231:155-72.

[31] Kwok J, Lim S. High-speed tribological properties of some Al/SiCp composites: I. Frictional and wear-rate characteristics. Composites Science and Technology. 1999;59:55-63.

[32] Rodriguez J, Poza P, Garrido M, Rico A. Dry sliding wear behaviour of aluminium-lithium alloys reinforced with SiC particles. Wear. 2007;262:292300 .

[33] Wilson S, Alpas A. Wear mechanism maps for metal matrix composites. Wear. 1997;212:41-9.

[34] Lim C, Lim S, Gupta M. Wear behaviour of SiCp-reinforced magnesium matrix composites. Wear. 2003;255:629-37.

[35] Cao L, Wang Y, Yao C. The wear properties of an SiC-whisker-reinforced aluminium composite. Wear. 1990;140:273-7.

[36] Wang A, Rack H. Transition wear behavior of SiC-particulate-and SiC-whiskerreinforced $7091 \mathrm{Al}$ metal matrix composites. Materials Science and Engineering: A. 1991;147:211-24.

[37] Ramesh C, Keshavamurthy R, Naveen G. Effect of extrusion ratio on wear behaviour of hot extruded Al6061-SiCp (Ni-P coated) composites. Wear. 2011;271:1868-77.

[38] Selvam B, Marimuthu P, Narayanasamy R, Anandakrishnan V, Tun K, Gupta M, et al. Dry sliding wear behaviour of zinc oxide reinforced magnesium matrix nano-composites. Materials \& Design. 2014;58:475-81.

[39] Sharifi EM, Karimzadeh F. Wear behavior of aluminum matrix hybrid nanocomposites fabricated by powder metallurgy. Wear. 2011;271:1072-9.

[40] Kök M, Özdin K. Wear resistance of aluminium alloy and its composites reinforced by $\mathrm{A} 12 \mathrm{O} 3$ particles. Journal of Materials Processing Technology. 2007;183:301-9.

[41] Buckley D, Johnson R. The influence of crystal structure and some properties of hexagonal metals on friction and adhesion. Wear. 1968;11:405-19. 